\title{
Globalization and perceptions of social inequality
}

Working Paper No. 32

\section{Malte Lübker}

Policy Integration Department

World Commission on the Social Dimension of Globalization

International Labour Office

Geneva

July 2004 
Copyright $($ International Labour Organization 2005

Publications of the International Labour Office enjoy copyright under Protocol 2 of the Universal Copyright Convention. Nevertheless, short excerpts from them may be reproduced without authorization, on condition that the source is indicated. For rights of reproduction or translation, application should be made to the Publications Bureau (Rights and Permissions), International Labour Office, CH-1211 Geneva 22, Switzerland. The International Labour Office welcomes such applications.

Libraries, institutions and other users registered in the United Kingdom with the Copyright Licensing Agency, 90 Tottenham Court Road, London W1T 4LP [Fax: (+44) (0)20 7631 5500; email: cla@cla.co.uk], in the United States with the Copyright Clearance Center, 222 Rosewood Drive, Danvers, MA 01923 [Fax: (+1) (978) 750 4470; email: info@copyright.com] or in other countries with associated Reproduction Rights Organizations, may make photocopies in accordance with the licences issued to them for this purpose.

ISBN 92-2-116680-5 (printed version)

ISBN 92-2-116681-3 (web version)

First published 2005

Cover:

The designations employed in ILO publications, which are in conformity with United Nations practice, and the presentation of material therein do not imply the expression of any opinion whatsoever on the part of the International Labour Office concerning the legal status of any country, area or territory or of its authorities, or concerning the delimitation of its frontiers.

The responsibility for opinions expressed in signed articles, studies and other contributions rests solely with their authors, and publication does not constitute an endorsement by the International Labour Office of the opinions expressed in them.

Reference to names of firms and commercial products and processes does not imply their endorsement by the International Labour Office, and any failure to mention a particular firm, commercial product or process is not a sign of disapproval.

ILO publications can be obtained through major booksellers or ILO local offices in many countries, or direct from ILO Publications, International Labour Office, CH-1211 Geneva 22, Switzerland. Catalogues or lists of new publications are available free of charge from the above address, or by email: pubvente@ilo.org

Visit our website: $\underline{w w w . i l o . o r g / p u b l n s}$

Printed by the International Labour Office, Geneva, Switzerland 


\section{Globalization and perceptions of social inequality}

\section{Contents}

Foreword iii

Preface $\mathbf{v}$

1. Globalization and perceptions of social inequality ...................................................................... 1

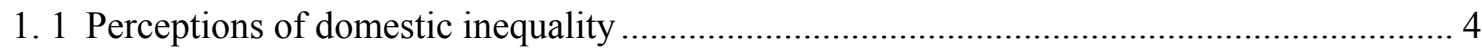

1.1.1 Disapproval of inequality and the endorsement of inequality as a trade off for prosperity. 5

1.1.2 Effects of the actual level of inequality on the perception of inequality................. 8

1.1.3 The perspective over time: Has the perception of inequality as being "too large" changed?.

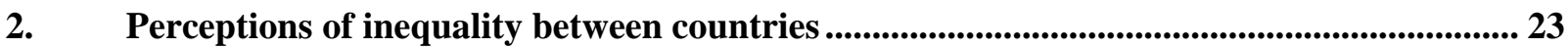

3. Support for redistributive government interventions......................................................................... 29

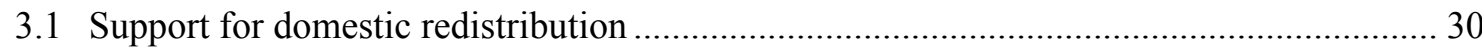

3.2 Explaining support for domestic redistribution: the role of self-interest and altruism ....... 39

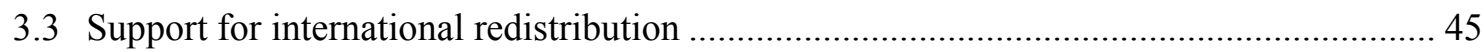

3.4 Explaining support for international redistribution: what are the views

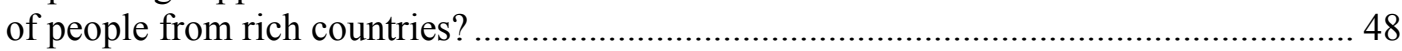

4. Conclusion: How supportive is public opinion of a more inclusive and equitable path for globalization? ......................................................................................................... 53

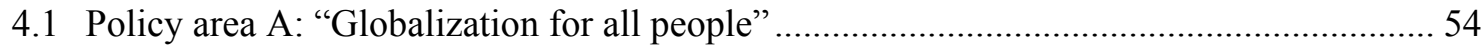

4.2 Policy area B: Globalization and the political process .................................................... 54

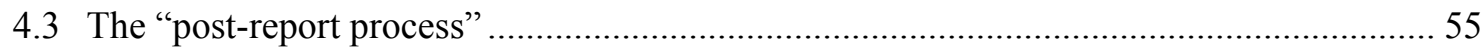

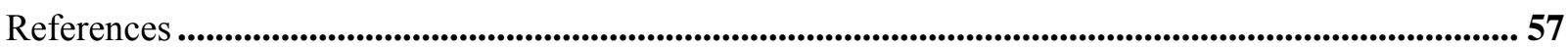

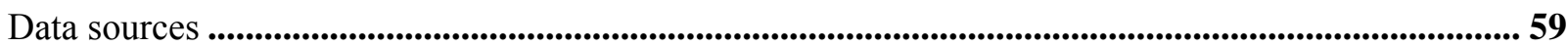

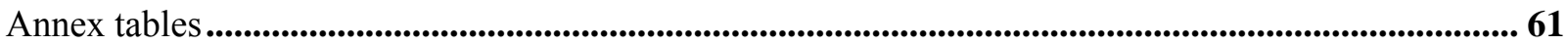




\title{
Foreword
}

In February 2002, the ILO established an independent World Commission on the Social Dimension of Globalization, co-chaired by President Tarja Halonen of Finland and President Benjamin Mkapa of Tanzania and comprising 26 eminent commissioners from a wide range of walks of life and different parts of the world, each serving in their individual capacity. Its broad goals were: to identify policies for globalization that reduce poverty, foster growth and development in open economies, and widen opportunities for decent work; to explore ways to make globalization inclusive, so that the process can be seen to be fair for all, both between and within countries; to promote a more focused international dialogue on the social dimension of globalization; to build consensus among key actors and stakeholders on appropriate policy responses; and to assist the international community forge greater policy coherence in order to advance both economic and social goals in the global economy.

The report of the World Commission, A fair globalization: Creating opportunities for all, was released on 24 February 2004. It is available on the Commission's website www.ilo.org/public/english/wcsdg/index.htm.

A secretariat was established by the ILO to support the Commission. Among other tasks, it compiled information and commissioned papers on different aspects of the social dimension of globalization. The aim was to provide the Commission with documentation and data on a wide range of options and opinions concerning subjects within its mandate, without committing the Commission or individual Commissioners to any particular position on the issues or policies concerned.

Material from this background work is being made available as working papers, as national and regional reports on meetings and dialogues, and in other forms. Responsibility for the content of these papers and publications rests fully with their authors and their publication does not constitute an endorsement by the World Commission or the ILO of the opinions expressed in them.

\author{
Gerry Rodgers \\ Director \\ Policy Integration Department
}





\section{Preface}

The Technical Secretariat to support the World Commission on the Social Dimension of Globalization first prepared a synthesis of ILO activities on the Social Dimension of Globalization (published as Working Paper No. 1 in this series). Documentation on the work and outcomes of other major commissions, an ideas bank, a database and knowledge networks of experts and social actors were subsequently developed. These networks have dealt with several topics, including: inclusion at the national level for the benefits of globalization to reach more people; local markets and policies; cross-border networks of production to promote decent work, growth and development; international migration as part of the Global Policy Agenda; international governance (including trade and finance); the relationship between culture and globalization; and values and goals in globalization. Gender and employment aspects were addressed throughout this work. The Reports on the Secretariat's Knowledge Network Meetings are available on the Commission's web site or in a special publication from the ILO (ISBN 92-2-115711-1).

During the course of these activities, a number of substantive background papers were prepared, which are now made available for wider circulation in the Policy Integration Department's Working Paper series (Nos. 16 to 38), as well as on the Commission's website.

The author, Malte Lübker of Halle University, argues in this paper that although there is still much heated debate on how, and whether, the growing integration of the world economy has caused greater social and economic differences, some broad trends are observable: Past decades have coincided with increasing inequality within a majority countries, and at the same time nation states have been under increasing pressure to reduce government interventions, a trend that has reduced their ability to apply redistributive policies. In addition many of the poorest countries have not gained from the potential benefits of globalization and fallen back further, increasing the gap between the poorest and the richest nations

While data on capital flows and trade, on cross-border debt and other economic aspects of globalization are readily available, far less is known about how people around the world perceive inequality both within their own country and between countries, and how supportive they are towards domestic and international redistribution. The present paper makes an attempt to reduce this gap by analysing survey data from the International Social Survey Programme that covers some thirty countries. The project started in 1987, and data are available until 1999. Lübker observes that ,compared to the late 80's people in almost all countries are increasingly sharing a concern for inequality and voicing solidarity with those who have so far not gained from globalization. There are exceptions and Lübker also discusses how these can be sensible dealt with.

\section{Rolph van der Hoeven \\ Manager, Technical Secretariat \\ World Commission on the Social Dimension of Globalization}

July 2004 



\section{Globalization and perceptions of social inequality}

Rising inequality is one of the most problematic aspects that accompany the current wave of globalization. While there is still much heated debate on how, and whether, globalization causes greater economic and social differences, some broad trends bring the issue onto the agenda:

- past decades of globalization have coincided with increasing inequality within countries;

- increased capital mobility leads to competition for investments between countries; since redistributive government interventions are increasingly perceived as an obstacle to investments, this could negatively affect governments willingness (and ability) to take action against inequality;

- so far globalization has seldom bridged, and often increased the gap between rich and poor countries.

However the debate around this will be solved, many people readily associate globalization with inequitable social outcomes and oppose it precisely for this reason; the antiglobalization movement builds on the feeling that the prevailing patterns are unjust and morally "bad". As it is argued in the initial inventory of issues, inequality is therefore an issue that needs to be addressed and managed if globalization is to be politically sustainable. If it is true that opposition to globalization and opposition to inequality are closely linked, the tolerance of inequality becomes a key factor in the political calculus. Protest from a tiny, if vocal, minority could be overridden if a majority of citizens shows little concern for inequality. In this case, globalization could be pushed ahead regardless of its social consequences. But if people resist rising income inequality, any policy that ignores this would run into increasing difficulties.

The present paper will investigate in how far people share the view that inequality is an issue that needs to be addressed, and to what extend people perceive present inequalities in their own countries as well as international inequalities as "too large". As Amartya Sen has argued, people's judgements about actual income distribution are a function of: (1) their ideas about what is morally right and just; and (2) the reality they compare these norms to (Sen 2000: 60). A statement like 'income is distributed too unevenly' by itself implies that the person who makes it must have some normative idea about what would constitute a proper, justifiable and fair distribution of income. However, the opposite would not hold true: if reality and a person's ideal match, she or he would disagree that inequality is too large and could nonetheless hold strong beliefs about the issue. Still, it is possible that people are largely insensitive to distributive aspects and perceive any distribution of income as morally just as long as everyone had her or his fair chance to succeed on the market. Outcome-oriented norms of distributive justice and goals such as 'to ensure a just share of the fruits of progress to all', an aim the ILO subscribed to in the Declaration of Philadelphia, are thus not necessarily shared by everyone. 
An indirect answer to the question whether outcome-oriented norms are a general component of people's value systems can be inferred by investigating how changes in inequality affect the perception of inequality: if people hold consistent beliefs about the fairness of income distribution, they should speak out against inequality the louder the higher actual inequality is. One analytical approach would be to compare perceptions across countries, the other to follow changes over time within countries. Both indirect and direct conclusions could be of relevance for policy area A, "Globalization for all people", that wants, among others, to explore the ethical foundations of a new vision of globalization that is build around issues such as inclusion and equality.

But what people think about inequality is also relevant for another reason: as demands on politicians, their views feed into the political process, the focus of policy area B. If a majority sees a situation as intolerable, policy makers have strong incentives to offer solutions and to act on the matter. In voicing and representing such concerns, parliaments and MPs have normally a linkage-function between the voters they represent and the governments that design and implement policies that shape globalization. This linkage function is a key feature of most normative theories of parliamentary democracy, and the idea is that this channel can ensure the political system's responsiveness to public demands (see Pitkin 1967). How well this process works in practice is open to investigation, but when making judgements about the outcomes of the political process, it is essential to know how people perceive these outcomes. This does not only apply to domestic inequality, but also to the global gap between rich and poor countries. Do people want their politicians only to look after their own country's welfare, or is international inequality a concern they would like to be addressed? If this were the case, policy-makers could hope for public support when they try to change policies to make them more favourable to those countries that have so far been excluded from the potential benefits of globalization.

There is thus also a direct link to the post-report process and the political feasibility of any proposals the World Commission may wish to make in order to promote a new, more equitable and inclusive path of globalization. Is public opinion supportive to ideas that require a certain element of altruism and solidarity with the fate of others? Or are people, and in particular those in the rich countries, not prepared to apply norms of equality and social justice outside the domestic context - and therefore respond with hostility to any policy that involves sharing some of their prosperity? In case the first possibility were true, this could be a strong argument to convince politicians that the policies identified by the World Commission could actually turn out to be politically feasible for them. Political leaders could build on public opinion that is open to such proposals and win support for them when they have the courage to make a convincing case for policies that benefit others as well as their immediate constituents. In doing so, they could address voters' moral beliefs about what is right and fair, rather than their narrow self-interest.

Data collected by the International Social Survey Programme (ISSP) can help to resolve some of these questions. The ISSP was founded in 1984 as a cross-national research collaboration for the social sciences and rapidly expanded beyond the four initial members ZUMA of Germany, NORC of the United States, SCPR of the United Kingdom and the Research School of Social Sciences in Australia. Other West European countries were the first to join, but a good number of transitional countries begun to participate during the late 1980s or early 1990s and countries like Canada, Israel, Japan, and New Zealand also became members. Since all participating institutions must fund their own research, developing countries are unfortunately under-represented - but data from Brazil, Chile, and 
the Philippines can still give some indication on views held in the developing world. In total, the ISSP currently has 38 members. They jointly design questionnaire modules on key topics of social research that are then translated from the English original and replicated over time to give cross-nationally and inter-temporal comparable results. The module relevant for the purpose of the present paper is the one on social inequality that has so far been used in three waves in 1987, 1992 and 1999. All three rounds contain views from citizens on inequality in their own country and on domestic redistribution. In 1999, several new questions were added that deal with inequality between rich and poor countries and international redistribution.

While there are several publications that make use of the two earlier waves (see e.g. the volume by Toš et al. 1999 and Gijsberts 1999), the approximately 30 national data-sets of the 1999 round have only been edited and merged in early 2002. As a consequence, only few publications have so far utilized these data. Among the papers published so far are those by Suhrcke (2001), who uses a preliminary and incomplete version of the data-set, and Redmond et al. (2002). Both have been written for a UNICEF project and put forward a detailed analysis of differences in the perception of inequality between East and West. To the best of the author's knowledge, no publication based on the ISSP 1999 round has so far dealt with an aspect crucial to the World Commission's work: attitudes towards inequality between poor and rich nations; and support for action against these international inequalities. Fortunately, the Zentralarchiv für Empirische Sozialforschung at the University of Cologne, that serves as the ISSP's administrative back office, has kindly granted permission to use the original data-sets for this technical paper. This makes not only sure that the most recent data can be used, but also that the key aspect of international inequalities can be taken into account.

The data on perceptions of inequality are matched with data on the actual extent of income inequality. The main source for this is the Luxembourg Income Study (LIS) that produced cross-nationally comparable Gini coefficients from household-level data-sets. They are based on 'disposable household income per person' and cover 18 of the countries also included in the ISSP data-sets. They were supplemented with data from Statistics New Zealand, who calculated LIS-compatible Gini coefficients, from the OECD for Japan and from the World Income Inequality Database (WIID) for seven further countries (see detailed listing in annex table 2). Only data from one primary source have been taken from the WIID compilation, and estimates comparable to the LIS were preferred, although in the case of the three developing countries Gini coefficients referring to gross income had to be used. For Cyprus and Portugal, only data of poor comparability were available and it was decided not to include any Gini coefficients for these two countries. Since the available sources - even if of acceptable quality - do not necessarily contain information for the three years the ISSP surveys were conducted, a simple linear interpolation method between the closest preceding year and the next following was used to estimate a Gini coefficient for the target year. In many cases, there was an entry for e.g. 1991 and 1994 so that estimating a figure for 1992 is unproblematic. In four cases (Australia, Czech Republic, Hungary and The Russian Federation), trends of the mid-1990s have been carefully extrapolated to 1999 since there was evidence available from an independent source that past trends indeed continued. ${ }^{1}$

${ }^{1}$ These extrapolations have been limited to 0.01 at the highest. 
The present paper will follow the questions already broadly outlined above; it is organized in three parts that each start with a description of the data and then approach an analytical question:

- perceptions of inequality within countries, how the level of inequality affects citizens' perception of income differences as 'too large', and how changes in inequality over time are mirrored in citizens' perceptions;

- perceptions of inequality between countries, and how the income level of the respondents' home country influences her or his view of international income differences;

- support for redistribution at the national and international level, how an individual's relative income position within a country influences his or her support for domestic redistribution, and how the fact that he or she lives in a rich or in a poor country influences his or her attitude towards an international redistributive tax.

The analysis will mainly be on the country-aggregate level, that is average perceptions will be compared across countries. These averages are calculated from the primary data-set by using a weight called weight 1 that corrects sampling errors and is available for 12 countries (respectively parts thereof: Great Britain, Northern Ireland, Austria, Hungary, Poland, Russian Federation, Canada, Philippines, Spain, France, Portugal, and Chile). ${ }^{2}$ When this is sensible, the aggregate-level analysis is supplemented by an individual level analysis that makes direct use of the merged original data-sets with some 30,000 respondents. This is especially useful when looking at factors such as and individual's self-placement in a social stratum that potentially influences her or his support for redistribution. The individual level data-set is weighted by weight 2 that builds on weight1, but also adjusts sample sizes across countries to the average of 1,221 respondents in order to give each country the same impact on the results. All tables are clearly marked to avoid confusion about the level of analysis.

\section{1 Perceptions of domestic inequality}

If, following Sen, people evaluate income differences against some particular notion of social justice, a brief look at the concept of social justice should precede the discussion of the survey-data. While Sen (2000) himself can be consulted for a more comprehensive review of the philosophical underpinnings provided by utilitarian, libertarian and Rawlsian theories as well as his own capabilities concept, it should suffice in the present context to point at two rival and potentially conflicting principles of social justice. First, social justice can be conceptualized in the sense of individualistic equity and equal opportunity, where society should keep open the roads of success to everyone and leave individuals in charge of their own economic progress or failure. The market is then seen as a system that distributes fair rewards according to achievement, and differences in income primarily reflect differences in effort or preference - if an individual chooses leisure over work, she or he is free to do so but will have to accept a lower income. Contrary to this, egalitarian conceptions of social justice focus on equality of outcomes. These are seen to be often

\footnotetext{
${ }^{2}$ For the United Kingdom, separate samples were drawn for Northern Ireland and Great Britain, and Germany is divided into its Eastern and Western parts.
} 
beyond an individual's direct influence and can be caused by factors like social barriers, missing ability, or simply bad luck. Those who fail on the market should be able to count on the solidarity of others, creating a closer social bond between the members of a given society. The State is seen as responsible to care for the welfare of its citizens, to prevent their social exclusion, and to give them a full and effective citizenship that includes social rights along with the traditional rights of freedom that derive from the liberal tradition.

Although both conceptions of social justice are potentially in conflict with each other, it would probably be misleading to see them as clear antipodes that exclude one another. Rather, it would appear as a matter of degree how much societies or individuals endorse either of the two paradigms. For the evaluation of income distribution, this should mean that the more prevalent egalitarian ideas are, and the less accepted the individualistic notion of equity is in a given society, the less tolerant should a society be to large differences in income. Public redistribution, the topic of section 3, should also find more support where egalitarian norms dominate, but would be seen as an act of injustice where the alternative conception prevails since high tax rates for the well-to-do deprive them of the rewards for their efforts.

\subsubsection{Disapproval of inequality and the endorsement of inequality as a trade off for prosperity}

The ISSP module on social inequality measured people's perception of domestic inequality by asking them to comment on the following statement:

Differences in income in [country] are too large.

where 'country' was substituted by the respondent's country of residence, but with 'Britain' and 'Northern Ireland' for the two sub-samples of the United Kingdom. Owed to the simple wording and the resulting low degree of difficulty, some 97 per cent of all respondents gave valid answers using the five answer categories provided: 'Strongly agree' (1), 'Agree' (2), 'Neither agree nor disagree' (3), 'Disagree' (4) and 'Strongly disagree' (5). For presentation in table 1, categories (1) and (2) have been collapsed into 'Agreement' and (4) and (5) into 'Disagreement'. 'Mean' is the simple average value for all answers.

The main result is quite striking: on average, 82.1 percent of the respondents from the 31 countries or regions listed in table 1 agreed with the statement that domestic income differences are too large, and only 7.7 per cent opposed this view. This demonstrates that a great majority of people around the world objects present economic conditions and that they must, to some degree, have internalized norms that prompt them to make such judgements about income distribution - they apparently do not restrict themselves to values such as equal opportunity, but go further in also looking into the outcome dimension of social justice.

Although in all countries a majority of at least roughly two-thirds holds the view that present income inequality is too big, there is some variation across countries. Agreement rates in excess of 95 per cent are found in Eastern European countries such as the Russian Federation, Bulgaria and Latvia, but also in Brazil and Portugal. At 93.6 per cent of agreement, East Germans evaluate income distribution far more critical than West Germans, of whom only 75.7 per cent share the view that income is distributed too unevenly in Germany. This already indicates that people who grew up in different societies can perceive identical things - in this case the income distribution of reunified Germany - quite differently (a topic that will be returned to later). In several other West European countries like the Netherlands, Norway, and Sweden, agreement rates are similar to those in West 
Germany, while Austrian, French and Spanish respondents condemn income distribution in their countries far more strongly. The lowest approval rates for the above statement - at around two-thirds - are found in Cyprus, the Philippines, Switzerland and the United States.

Table 1. Perception of domestic inequality as "too large", 1999 or latest available year

\begin{tabular}{|c|c|c|c|}
\hline & Agreement & Disagreement & Mean \\
\hline Australia & 70.9 & 12.0 & 2.24 \\
\hline Austria & 86.2 & 4.7 & 1.78 \\
\hline Brazil & 95.5 & 3.1 & 1.23 \\
\hline Bulgaria & 96.8 & 1.7 & 1.22 \\
\hline Canada & 70.6 & 13.8 & 2.18 \\
\hline Chile & 92.2 & 4.5 & 1.70 \\
\hline Cyprus & 65.6 & 12.6 & 2.35 \\
\hline Czech Republic & 87.8 & 6.3 & 1.60 \\
\hline France & 87.4 & 5.2 & 1.56 \\
\hline Germany East & 93.6 & 6.4 & 1.63 \\
\hline Germany West & 75.7 & 10.0 & 2.15 \\
\hline Great Britain & 82.4 & 6.0 & 1.93 \\
\hline Hungary & 93.1 & 3.5 & 1.44 \\
\hline Israel & 89.8 & 6.2 & 1.63 \\
\hline Italy (1992) & 89.2 & 3.9 & 1.62 \\
\hline Japan & 69.1 & 12.5 & 2.10 \\
\hline Latvia & 96.7 & 1.5 & 1.48 \\
\hline Netherlands (1987) & 76.3 & 11.4 & 2.38 \\
\hline New Zealand & 73.2 & 13.4 & 2.12 \\
\hline Northern Ireland & 69.5 & 9.1 & 2.23 \\
\hline Norway & 72.5 & 13.8 & 2.21 \\
\hline Philippines & 65.3 & 17.8 & 2.34 \\
\hline Poland & 89.1 & 4.7 & 1.70 \\
\hline Portugal & 96.0 & 2.3 & 1.25 \\
\hline Russian Federation & 95.5 & 2.3 & 1.28 \\
\hline Slovakia & 93.7 & 1.8 & 1.35 \\
\hline Slovenia & 91.0 & 4.2 & 1.64 \\
\hline Spain & 89.3 & 3.3 & 1.78 \\
\hline Sweden & 71.1 & 10.8 & 2.13 \\
\hline Switzerland (1987) & 67.5 & 11.8 & 2.27 \\
\hline United States & 66.2 & 12.4 & 2.24 \\
\hline Average & 82.1 & 7.7 & 1.85 \\
\hline \multicolumn{4}{|c|}{$\begin{array}{l}\text { Note: Respondents were asked to comment on the following statement: 'Differences in income in [country] are too large'. The } \\
\text { answer categories given were 'Strongly agree' (1), 'Agree' (2), 'Neither agree nor disagree' (3), 'Disagree' (4) and 'Strongly } \\
\text { disagree' (5). Categories ( } 1 \text { ) and (2) have been collapsed into 'Agreement' and (4) and (5) into 'Disagreement'. 'Mean' is the } \\
\text { simple average value for all answers from a given country. Weighted by weight1. Source: Author's calculations based on ISSP } \\
\text { data-sets. }\end{array}$} \\
\hline
\end{tabular}


Table 2. Endorsement of inequality as a trade-off for prosperity, 1999 or latest available year

\begin{tabular}{|c|c|c|c|}
\hline & Agreement & Disagreement & Mean \\
\hline Australia & 20.2 & 46.3 & 3.33 \\
\hline Austria & 14.0 & 65.0 & 3.76 \\
\hline Brazil & 43.9 & 47.8 & 3.08 \\
\hline Bulgaria & 14.4 & 72.7 & 4.12 \\
\hline Canada & 16.6 & 64.7 & 3.65 \\
\hline Chile & 47.3 & 38.0 & 2.91 \\
\hline Cyprus & 6.8 & 71.7 & 3.87 \\
\hline Czech Republic & 19.2 & 63.7 & 3.70 \\
\hline France & 15.8 & 65.1 & 3.74 \\
\hline Germany East & 18.0 & 54.1 & 3.49 \\
\hline Germany West & 29.6 & 44.7 & 3.22 \\
\hline Great Britain & 17.9 & 57.8 & 3.48 \\
\hline Hungary & 13.1 & 75.5 & 3.93 \\
\hline Israel & 29.4 & 54.9 & 3.34 \\
\hline Italy (1992) & 32.4 & 44.4 & 3.24 \\
\hline Japan & 27.6 & 40.7 & 3.30 \\
\hline Latvia & 18.3 & 70.4 & 3.76 \\
\hline Netherlands (1987) & 16.9 & 62.1 & 3.59 \\
\hline New Zealand & 19.3 & 61.0 & 3.54 \\
\hline Northern Ireland & 18.0 & 54.7 & 3.45 \\
\hline Norway & 16.8 & 57.0 & 3.50 \\
\hline Philippines & 53.6 & 24.5 & 2.62 \\
\hline Poland & 27.7 & 57.3 & 3.35 \\
\hline Portugal & 26.9 & 59.5 & 3.59 \\
\hline Russian Federation & 15.2 & 73.8 & 4.05 \\
\hline Slovakia & 9.9 & 78.4 & 4.18 \\
\hline Slovenia & 22.1 & 63.9 & 3.61 \\
\hline Spain & 27.9 & 51.8 & 3.33 \\
\hline Sweden & 20.8 & 49.1 & 3.41 \\
\hline Switzerland (1987) & 17.5 & 57.6 & 3.52 \\
\hline United States & 27.4 & 42.7 & 3.19 \\
\hline Average & 22.7 & 57.1 & 3.51 \\
\hline \multicolumn{4}{|c|}{$\begin{array}{l}\text { Note: Respondents were asked to comment on the following statement: 'Large differences in income are necessary for [country's] } \\
\text { prosperity'. The answer categories given were 'Strongly agree' (1), 'Agree' (2), 'Neither agree nor disagree' (3), 'Disagree' (4) and } \\
\text { 'Strongly disagree' (5). Categories (1) and (2) have been collapsed into 'Agreement' and (4) and (5) into 'Disagreement'. 'Mean' is } \\
\text { the simple average value for all answers from a given country. Weighted by weight1. } \\
\text { Source: Author's calculations based on ISSP data-sets. }\end{array}$} \\
\hline
\end{tabular}


As Kluegel and Smith (1986) and also Kluegel and Mathìjù (1995) have argued, there is the possibility that people make contradictory or even mutually excluding judgements about inequality and support both egalitarian and inegalitarian norms. It is therefore worth to counter-check the results presented above by looking at an item from the ISSP questionnaire that presented inequality as an acceptable trade-off for prosperity:

Large differences in income are necessary for [country's] prosperity.

Again, respondents were asked to record their support for this statement on a five-pointscale ranging form 'Strongly agree' (1) to 'Strongly disagree' (5); the results are found in Table 2. As a general pattern, the agreement with this item was greatest in countries where people were less concerned about income differences. The correlation is significant at the 0.05-level and, with a Pearson's $r$ of -0.397 (aggregate level data-set), quite strong. A perfect correlation should not be expected since the perception of domestic inequality as 'too large' is not only influenced by norms, but also by the actual extent of inequality, whereas the latter statement abstracts from prevailing conditions.

A somewhat remarkable pattern is that the three developing countries (Brazil, Chile, and the Philippines) show extraordinary high approval rates at over 40 per cent, but also displayed almost unanimous (Brazil and Chile) or strong agreement (the Philippines) with the statement that income inequality is too large. People here seem to consider inequality as an extremely regrettable, but somehow necessary evil. ${ }^{3}$ This would support the split-consciousness hypothesis as put forward by Kluegel and Smith (1986) for these somewhat special cases; if they are excluded from the analysis, the correlation coefficient rises to an astonishing -0.625 (significant at the 0.000-level, aggregate level data-set). For the remaining countries, there is thus a very strong consistency of general attitudes towards inequality: the more a society agrees with a statement based on an egalitarian conception of social justice, the less will it support a statement that sees inequality from a more positive side (as conceptions stressing individualistic equity would). ${ }^{4}$

\subsubsection{Effects of the actual level of inequality on the perception of inequality}

While the widespread agreement with the statement that domestic inequality is too high already indicates that people must have some idea about what would constitute a fair and justifiable distribution of income, the results presented so far do not indicate how consistently norms are applied across different societies. This leads to the analytical question this sub-section wants to answer: Does the perception that inequality is 'too high' vary with the actual level of inequality in the respondent's country?

\footnotetext{
${ }^{3}$ Much of the earlier literature on inequality and development shared such a view (e.g. Kaldor 1958), but more recent research has questioned the idea that inequality is a prerequisite for growth and presented some evidence that suggests the opposite holds true (see Aghion et al. 1999).

${ }^{4}$ For a more detailed analysis on the level of individuals, see also Gijsberts (1999: 42ff.).
} 
- A first possibility, the null hypothesis, is that the perception of domestic inequality differs randomly between countries, showing no relationship to the country's actual level of income inequality. What is perfectly acceptable in one country could be seen as intolerable in another; different societies have different ideas about the 'appropriate' level of inequality. Outcome-oriented norms of social justice would then be contingent to a particular society at a particular point in time.

- The alternative hypothesis 1a) is that the perception of present inequality in a specific country is a function of inequality in that country. Again following Sen's idea, people would evaluate the present situation in their own country against the same universal concept of social justice. Present inequality should then be perceived as less acceptable the higher the actual level of inequality is in a country. A possible modification that emerges from the previous discussion is that conceptions of social justice differ between different cultural hemispheres, types of welfare regimes or otherwise specified groups of countries, but are applied consistently within these groupings. This will be referred to as hypothesis $1 b$ ).

To test the above hypotheses, the perception of inequality as the dependent variable will be regressed against the Gini index as a measure of income distribution. Sources for the latter are found in annex Table 2; since no data of appropriate quality were found for Cyprus and Portugal, these two countries are excluded from the analysis. Italy, the Netherlands, and Switzerland, who participated in earlier rounds of the ISSP but not in 1999, are included with their results from 1987 and 1992 respectively, and with a Gini index for the same year.

Before discussing the actual regression results, a first impression can be gained from the graphical presentation of the results in chart 1: most countries are clustered on the left-hand side of the scatter-plot with Gini coefficients between 0.20 and 0.40 , while the Russian Federation and the three developing countries are located further to the right. Going by the chart, there is no apparent relationship between the Gini index and the perception of inequality: for instance, although the Netherlands and the Czech Republic display very similar levels of inequality, the Czech (mean: 1.60) oppose the situation in their country far more strongly than the Dutch (mean: 2.38); the same would hold true for the average Italian who evaluates the situation far more negatively than a Canadian, although both living in countries with a Gini index of around 0.30. On the other hand, Swedish citizens and respondents from New Zealand on average agree that income differences are 'too large' (with means around 2.1), although they are actually far bigger in New Zealand (with a Gini index of 0.33) than in Sweden (Gini index: 0.22). Regression (1) in Table 3 (that is found four pages onwards) confirms the impression that no significant relationship between the perception of inequality (the dependent variable) and the Gini index, that is used as an explanatory variable, exists. The alternative hypothesis 1a) is thus not confirmed; there is apparently no single, universal concept of social justice that is homogeneously applied in all countries.

This, however, does not mean that the Gini coefficient has no influence on the perception of inequality and that people make random assessments of the situation - and that any level of inequality is as good as any other. Even if the existence of a single, universal outcome-oriented concept of social justice is not supported by the data, this still leaves open the possibility laid out in hypothesis 1b) above: that different groups of countries accept egalitarian norms to different degrees, but that these norms are applied consistently within groups of countries. 
A strong candidate for such a group are the transitional countries of Eastern Europe. Here, people grew up in systems whose ideology advocated the elimination of class differences and they experienced a reality that, although not living up to this goal, had extremely low levels of inequality by any historic or international standards. In addition to the direct effects of a predominant ideology on the formation of people's values, the past experience of low inequality could also serve as a frame of reference that forms today's expectations about what one can legitimately expect to be the case (see Arts and Gelissen 2001). In his comparison between 'East' and 'West', Suhrcke (2001) found confirmation (?) that East Europeans are far more critical towards inequality than people from other countries. Gijsberts (1999) also presented evidence that egalitarian justice principles are more widespread in Eastern Europe than in the West. The transitional countries thus seem to be a useful category and, for the present paper, East Germany will be grouped with them, given the fact that East Germans share a common history with people from the remainder of the former communist block and differ in their attitudes from their Western compatriots (see also Wegener and Liebig 1995).

\section{Figure 1. Perception of domestic inequality as "too large" and Gini index}

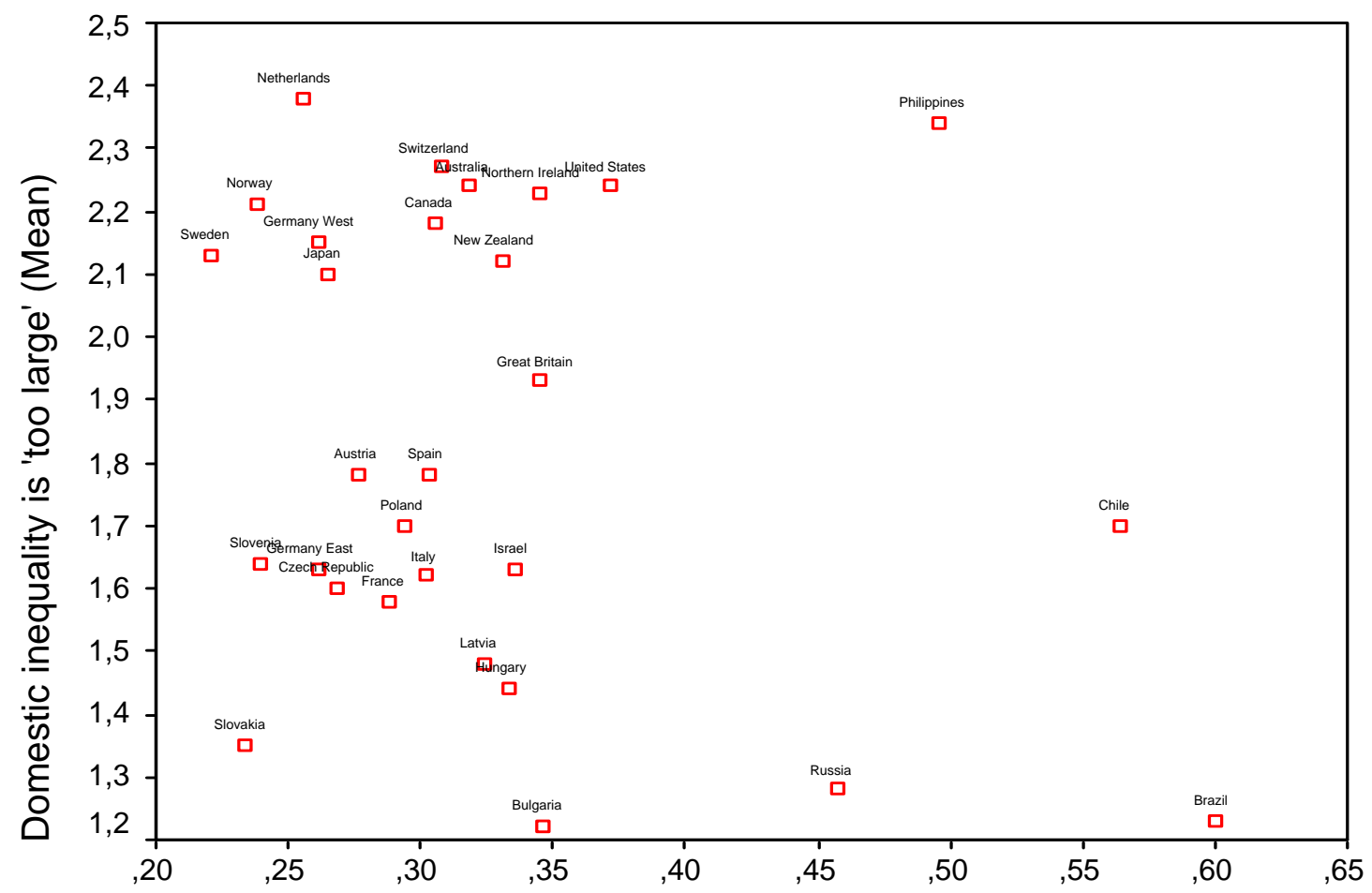

\section{Gini-Index}

Source: Author's calculations based on ISSP data-sets, for Gini coefficients, see annex Table 2.

While grouping the countries of the 'East' will hardly be controversial, other research indicates that lumping all the industrialized nations under the label 'West' might ignore crucial differences between them. Comparative studies on attitudes towards social justice highlight that inequality is seen much more favourably in the United States than in Europe (Alesina, di Tella and MacCulloch 2001), and particularly in Germany (Wegener and Liebig 1995; see also Roller 2000). But even within Europe, there is a great deal of variation. Svallfors (1993) shows that the British are prepared to accept far bigger differences between wealthy groups and the worst-off than the Swedish would tolerate. Esping-Andersen 
classifies both Britain and the United States, alongside with other Anglo-Saxon countries, as 'liberal' welfare states were "the progress of social reform has been severely circumscribed by traditional, liberal work-ethic norms" (Esping-Andersen 1990: 26). As a result, the Anglo-Saxon countries offer only modest social benefits that are tied to strict entitlement rules, and the idea of social rights is effectively contained (ibid.). While Roller (2000) emphasizes that minimal welfare provisions are supported even in the United States, Wegener and Liebig (1995) show that an ideology they call "self-interested individualism" dominates in the United States and contrast this with the "egalitarian statism" they detected in Germany. The present paper follows Esping-Andersen and groups the Anglo-Saxon countries of the sample (Australia, Canada, Great Britain, New Zealand, Northern Ireland, and the United States) for analytical purposes.

While Esping-Andersen further differentiates between the "conservative" and the "social democratic" welfare regimes of continental Europe, this distinction will not be made here. This is not only due to the fact that the "social democratic" type is limited to the two Scandinavian countries in the sample (Norway and Sweden), but also because there are important similarities with the rest of continental Europe: all have in principle accepted the notion of social rights and, albeit to different degrees, a responsibility of the State to care for the welfare of its citizens. Welfare systems are generally far more extended and go beyond providing the minimum necessary for bare physical survival, although they might be even more generous in Scandinavia than elsewhere. In contrast to the liberal market economies of the Anglo-Saxon world, most continental European countries have some kind of corporatist arrangements, rely less on market forces, know more state regulation and have higher tax rates. They are sometimes classified as "organized market economies", and this term rather than continental European - will be adopted as an analytical category; it has the advantage that it can also be applied to the two non-European, non Anglo-Saxon industrialized nations of the sample, Israel and Japan. ${ }^{5}$ Since citizens' attitudes in this group can be expected to lie somewhere between the transitional and the Anglo-Saxon countries, the organized market economies will be used as the omitted benchmark category in the following regressions.

This leaves us with only three countries that have so far not been included in any group: Brazil, Chile and the Philippines. They will simply be referred to as 'developing countries' and share extraordinary high levels of inequality. Also, these were the three countries showing some signs of 'split-consciousness' by endorsing both egalitarian norms and the view that inequality is necessary for prosperity. Having them jointly in one group also isolates the three countries where only Gini coefficients that refer to gross (instead of net) income were available.

Dividing the ISSP sample into four clusters is not to deny that considerable differences between countries of the same cluster exist, say between Sweden and Spain or the United States and Canada. It is simply to argue that Sweden has more in common with Spain than with the Anglo-Saxon countries, and that the United States and Canada have more commonalties between them than with either Spain or Sweden. There are, of course, some borderline cases. One could argue that Britain, going by the attitudes of its citizens, is more European than many British would admit and is misplaced alongside her overseas offspring; or that the particular course the reformation took in the Netherlands and in Switzerland draws a sharp line between them and the Lutheran and Catholic parts of continental Europe, and that they would be more appropriately placed with the United States. However, there are

${ }^{5}$ The island of Cyprus is another case where 'continental European' would be misleading. 
counter-arguments to this and on the whole the four groups seem to provide a defendable analytical distinction.

Figure 2 splits the sample along these lines and the four scatter plots show a number of clear regularities. This is most evident for the transition countries and the organized market economies, for which the countries are distributed along an imagined descending line. The further to the right, the higher the Gini index the more strongly people agree that domestic inequality in their country is too wide. The same can be observed for the developing countries although, due to the small sample size, the findings for these countries should be interpreted with caution. The Anglo-Saxon group displays a less clear-cut pattern. Respondents from the United States seem to care little about income inequality in their country, despite its extraordinarily high level. At the other extreme, the British, who experience considerably lower levels of income inequality, speak out against it quite strongly.

Nonetheless, the first impression already leads to the presentiment that the evidence supports hypothesis 1(b), which suggests that norms of distributive justice vary between groups of countries, but are applied more consistently within these groups. Regression (2) in Table 3 offers a formal test by entering three dummy variables for the transition, AngloSaxon and developing countries (omitting the benchmark category "organized market economies"). With more than half of the variance explained $\left(\mathrm{R}^{2}=0.609\right)$, the explanatory power of the regression is quite strong. All of the dummies turn out to be significant, as does the Gini index. Once cultural and historical differences between countries are taken into account, the actual level of inequality therefore has a measurable impact on perceptions of income differences. The wider they are the more people oppose them. Increasing the Gini index by 0.1 would move the perception of income differences as being "too large" by roughly one-third of a category, for example from "agree" towards "strongly agree". This supports Sen's argument that the perception of inequality is a function of the actual extent of inequality and the norms against which the current situation is evaluated, and also that these norms show some consistency within groups of culturally similar countries.

Figure 2. Perception of domestic inequality as "too large" and the Gini index by groups of countries

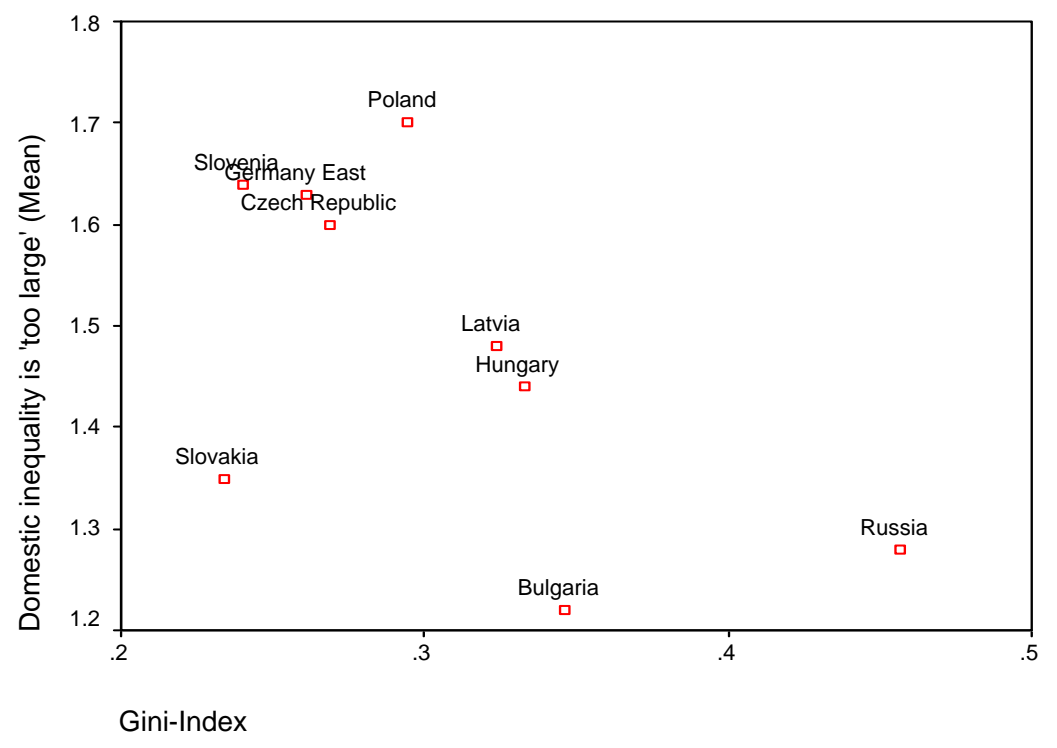


There are quite remarkable differences between the four groups, as shown up in the dummy variables. In a situation in which respondents from the organized market economies, used here as the benchmark, would on average respond with "agree" (coded 2.0) to the statement that inequality in their country is too large (this would be the case at a Gini index of 0.266), citizens from the transition countries would on average agree far more strongly (moving 0.397 steps towards "strongly agree", resulting in a hypothetical mean of 1.603), while those from Anglo-Saxon countries would agree less strongly (with a hypothetical mean of 2.366). Or, put another way, while it would require a Gini index of 0.266 in the organized market economies to make people on average "agree" that income differences are too large, the same response would be obtained at a far lower level of inequality in the transition countries (at a Gini of 0.135), while people in the Anglo-Saxon countries would only agree that inequality is "too large" at a Gini of 0.388 . The figure is even higher in the developing countries, at 0.472 . This shows once again that societies from the four groups differ strikingly in their tolerance of income differences.
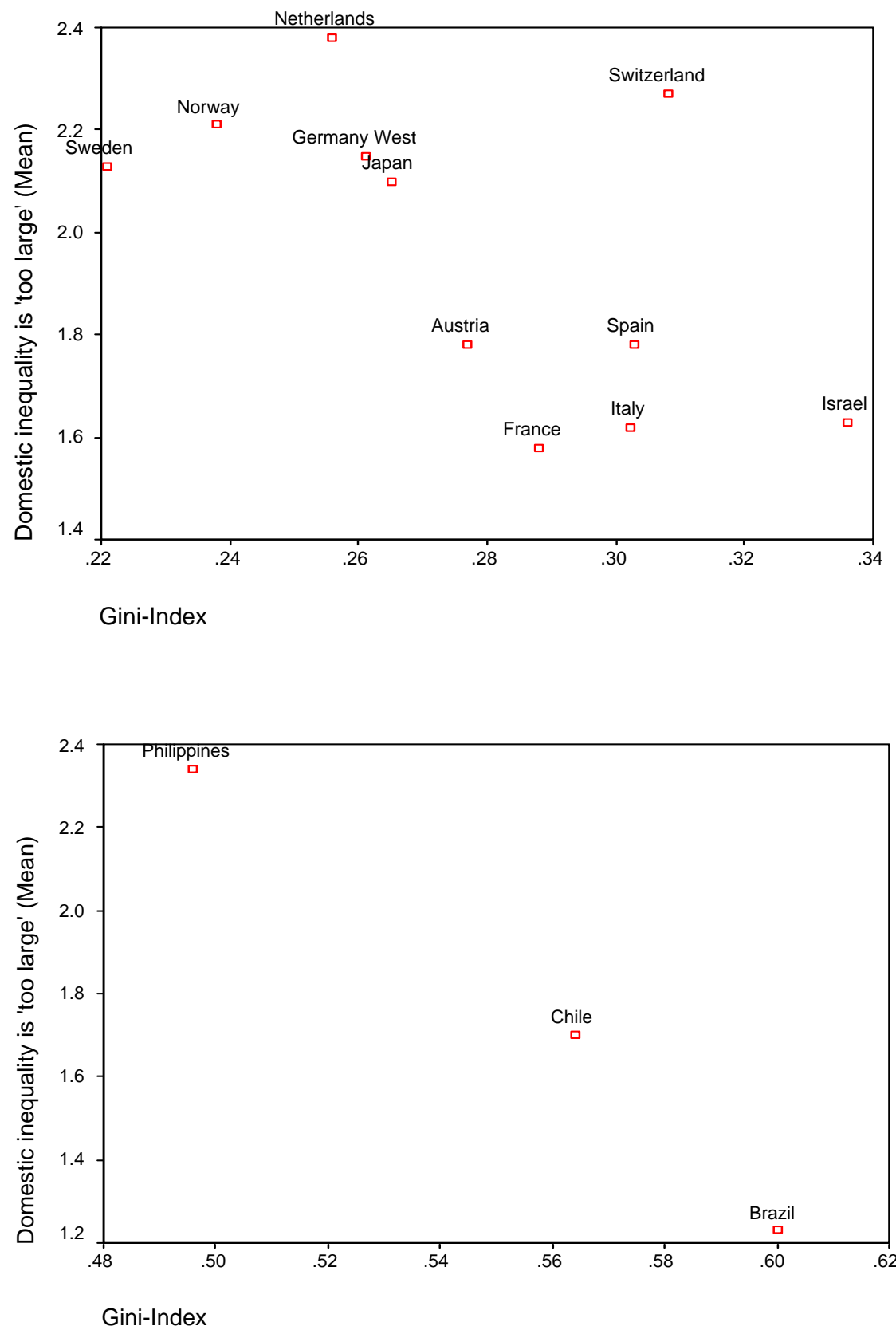
Table 3. Perception of domestic inequality and Gini index, aggregate level regression

\begin{tabular}{lcccccc}
\hline & \multicolumn{3}{c}{ (1) } & \multicolumn{3}{c}{ (2) } \\
\cline { 2 - 7 } & Coef. (b) & Std. err. & Sign. & Coef. (b) & Std. err. & Sign. \\
\hline Constant & 2.127 & 0.250 & 0.000 & 2.805 & 0.272 & 0.000 \\
Gini index & -0.896 & 0.734 & 0.233 & -3.021 & 0.946 & 0.004 \\
Dummy transition & & & & -0.397 & 0.106 & 0.001 \\
Dummy Anglo-Saxon & & & & 0.366 & 0.126 & 0.009 \\
Dummy developing & & & & 0.623 & 0.300 & 0.049 \\
R $^{2}$ (adjusted) & 0.017 & & 0.233 & 0.609 & & 0.000
\end{tabular}

Note: Dependent variable is "Differences in income in [country] are too large". Based on aggregate level data set, number of valid observations = 29 (including Italy, Netherlands and Switzerland, but excluding Cyprus and Portugal). Source: Author's calculations based on ISSP data sets.

Table 4. Perception of domestic inequality, endorsement of inequality and Gini index, aggregate level regression

(3) (4)

\begin{tabular}{lcccccc} 
& Coef. (b) & Std. err. & Sign. & Coef. (b) & Std. err. & Sign. \\
\hline Constant & 5.183 & 0.709 & 0.000 & 4.089 & 0.665 & 0.000 \\
Gini index & -2.125 & 0.626 & 0.002 & -2.558 & 0.913 & 0.010 \\
Endorsement & -0.759 & 0.170 & 0.000 & -0.409 & 0.196 & 0.048 \\
Dummy transition & & & & -0.268 & 0.117 & 0.032 \\
Dummy Anglo-Saxon & & & & 0.335 & 0.121 & 0.011 \\
Dummy developing & & & & 0.258 & 0.331 & 0.444 \\
$\mathrm{R}^{2}$ (adjusted) & 0.424 & & 0.000 & 0.657 & & 0.000
\end{tabular}

Note: Dependent variable is "Differences in income in [country] are too large". "Endorsement" refers to "Large differences in income are necessary for [country's] prosperity". Based on aggregate level data set, number of valid observations = 29 (including Italy, Netherlands and Switzerland, but excluding Cyprus and Portugal).

Source: Author's calculations based on ISSP data sets. 
Table 5. Perception of domestic inequality and Gini index, individual level regression

\begin{tabular}{lcccccc}
\hline & \multicolumn{3}{c}{$(\mathbf{5})$} & & \multicolumn{3}{c}{ (6) } \\
\cline { 2 - 7 } & Coef. (b) & Std. err. & Sign. & Coef. (b) & Std. err. & Sign. \\
\hline Constant & 2.038 & 0.019 & 0.000 & 2.738 & 0.031 & 0.000 \\
Gini index & -0.715 & 0.055 & 0.000 & -2.995 & 0.107 & 0.000 \\
Dummy transition & & & & -0.339 & 0.013 & 0.000 \\
Dummy Anglo-Saxon & & & & 0.423 & 0.015 & 0.000 \\
Dummy developing & & & & 0.676 & 0.034 & 0.000 \\
R $^{2}$ (adjusted) & 0.005 & & 0.000 & 0.103 & & 0.000
\end{tabular}

Note: Dependent variable is "Differences in income in [country] are too large". Based on individual level data set, number of valid observations $\geq 30,000$ (excluding Cyprus, Italy, Netherlands, Portugal and Switzerland). Weighted by weight2.

Source: Author's calculations based on ISSP data sets.

Table 6. Perception of domestic inequality, endorsement of inequality and Gini index, individual level regression

(7) (8)

\begin{tabular}{lcccccc} 
& Coef. (b) & Std. err. & Sign. & Coef. (b) & Std. Err. & Sign. \\
\hline Constant & 2.796 & 0.027 & 0.000 & 3.250 & 0.034 & 0.000 \\
Gini index & -1.006 & 0.056 & 0.000 & -2.932 & 0.110 & 0.000 \\
Endorsement & -0.188 & 0.005 & 0.000 & -0.153 & 0.004 & 0.000 \\
Dummy transition & & & & -0.291 & 0.013 & 0.000 \\
Dummy Anglo-Saxon & & & & 0.415 & 0.015 & 0.000 \\
Dummy developing & & & & 0.577 & 0.035 & 0.000 \\
$\mathrm{R}^{2}$ (adjusted) & 0.060 & & 0.000 & 0.137 & & 0.000
\end{tabular}

Note: Dependent variable is "Differences in income in [country] are too large". Based on individual level data set, number of valid observations $\geq 30,000$ (excluding Cyprus, Italy, Netherlands, Portugal and Switzerland). Weighted by weight2.

Source: Author's calculations based on ISSP data sets.

These differences by and large remain, even when endorsement of inequality as a trade-off for prosperity is entered as an additional explanatory variable, although the differences are less pronounced. ${ }^{6}$ If added without the group dummies, as in regression (3) in Table 4, the variables "Gini index" and "endorsement" are quite good predictors of perceptions of inequality in a given society $\left(\mathrm{R}^{2}=0.424\right)$. The negative sign of the coefficient for "endorsement" means that the more accepted the idea that inequality is good for prosperity, the less inequality is seen as a problem. This again supports the underlying idea that perceptions of inequality are a function of norms, in this case the endorsement of an inegalitarian argument for inequality, and the actual extent of inequality, as captured by the Gini index.

${ }^{6}$ The dummy for the developing countries even loses its significance in regression (4) in Table 4. 
While societies have up to now been compared on the aggregate level, it is worth testing the results by making direct use of the individual level data set. The basic specification, with the perception of inequality as the dependent variable and the Gini index as an explanatory variable, now turns out to be significant, but the explanatory power of regression (5) in Table 5 is negligible, at only half a per cent. The adjusted $\mathrm{R}^{2}$ rises to 0.103 when the group dummies are added, with the dummies themselves taking values similar to those in the aggregate level regression. This can be seen as supporting the previous finding that values and tolerance of inequality differ greatly between groups of countries. Adding the variable "endorsement" alongside the Gini index, as in regression (7) in Table 6, has the same effect as on the aggregate level. It yields a significant coefficient and increases the explanatory power compared to regression (5). Moreover, the group dummies entered in regression (8) further improve the explanatory power.

\subsubsection{The perspective over time: Has the perception of inequality as being "too large" changed?}

An alternative approach to the above cross-country analysis is to investigate how perceptions of inequality have changed within countries over time, and then to link these changes to the changes in actual inequality. On this basis, conclusions can then be drawn about the consistency of values over time. The obvious research question is whether increases (decreases) in actual inequality lead to increases (decreases) in the perception of inequality as being "too high". Once again, there are two possible answers:

- The null hypothesis would be that changes in perceptions are independent of trends in inequality. In particular, increases in inequality do not lead to an increase in the percentage of people who say that there is "too much inequality". One possible and often cited explanation for this is a Hirschman-type "tunnel effect", whereby people do not perceive the progress of others as negative, even if their own income position stagnates. On the contrary, the progress of a minority could signal that they might be the next to profit from economic growth. In such a context, people could therefore tolerate a temporary shift in inequality (see Hirschman, 1973; see also Ravallion and Lokshin, 1999).

- The alternative hypothesis is that increases in inequality result in a higher percentage of respondents perceiving inequalities as being "too high". This would indicate that the same concept of social justice is applied consistently over time. If the value component of Sen's equation remains constant, any changes in inequality should translate directly into a changed perception of inequality. 
Although these seem to be the two most likely answers to the question raised above, it should be emphasized that the data available from the ISSP project may not be sufficient to reach a more than tentative conclusion. In the first place, very little time passed between the survey rounds (five years from 1987 to 1992 and seven years between 1992 and 1999). There is the additional problem that not all countries participated from the start, and that some of the initial participants later dropped out of the project. This leads to a very low number of cases. In total, there are only 24 "spells" with data from two points in time, which is less than would normally be needed to identify significant relationships. A failure to reject the null hypothesis could therefore also be due to the inadequacy of the data, even if a significant (but unobserved) relationship existed in reality.

But even with these data limitations, examination of the trends over time can undoubtedly provide an answer to a more straightforward question: "Do people increasingly see inequality as a problem, or has the issue become less pressing for them?" Tables 7 and 8 list the perceptions of inequality in 1987/92 and 1992/99 respectively; a standard $t$-test for two independent samples was used to establish whether changes significant at the 0.05 -level occurred between the two survey rounds. Table 7 shows that the perception of inequality as being "too large" rose in six countries between 1987 and 1992. The change was greatest in the United States, with a mean of 2.50 (between "agree" and "neither agree nor disagree") in 1987, but a mean of 2.08 in 1992, which is already very close to "agree". Great Britain and West Germany also experienced relatively large increases in public awareness of inequality (both with changes of 0.19 points). In Australia, Hungary and Italy, people also spoke out against inequality more strongly in 1992 than in 1987. However, the relatively small change in Poland was not significant and the perception of inequality is therefore considered to be "stable". Austria is the only country in the sample in which respondents agreed less with the statement that income differences are "too large" in 1992 than in 1987. If responses from all eight countries are averaged (giving every country equal weight), a significant increase in perceptions of inequality as being "too large" can be shown between the two years. 
Table 7. Perception of domestic inequality and Gini index, 1987-92

\begin{tabular}{|c|c|c|c|}
\hline & 1987 & 1992 & Trend \\
\hline Australia & 2.48 & 2.38 & Perception up \\
\hline Std. dev. & $(1.01)$ & $(1.02)$ & \\
\hline Gini & 0.298 & 0.308 & Increase \\
\hline Germany West & 2.12 & 1.93 & Perception up \\
\hline Std. dev. & $(0.95)$ & $(0.84)$ & \\
\hline Gini $^{*}$ & 0.248 & 0.255 & Increase \\
\hline Great Britain & 2.10 & 1.91 & Perception up \\
\hline Std. dev. & $(0.95)$ & $(0.92)$ & \\
\hline $\operatorname{Gini}^{* *}$ & 0.310 & 0.337 & Sharp increase \\
\hline United States & 2.50 & 2.08 & Perception up \\
\hline Std. dev. & $(1.03)$ & $(0.96)$ & \\
\hline Gini & 0.335 & 0.342 & Increase \\
\hline Austria & 1.71 & 1.91 & Perception down \\
\hline Std. dev. & $(0.82)$ & $(0.90)$ & \\
\hline Gini & 0.227 & 0.258 & Sharp increase \\
\hline Hungary & 1.96 & 1.80 & Perception up \\
\hline Std. dev. & $(1.05)$ & $(0.94)$ & \\
\hline Gini & 0.273 & 0.296 & Sharp increase \\
\hline Poland & 1.85 & 1.82 & Stable perception \\
\hline Std. dev. & $(1.03)$ & $(0.92)$ & \\
\hline Gini & 0.272 & 0.274 & Stable \\
\hline Italy & 1.76 & 1.62 & Perception up \\
\hline Std. dev. & $(0.85)$ & $(0.79)$ & \\
\hline Gini & 0.303 & 0.302 & Stable \\
\hline \multirow[t]{2}{*}{ All countries } & 2.07 & 1.93 & Perception up \\
\hline & $(1.00)$ & $(0.93)$ & \\
\hline Average Gini & 0.283 & 0.297 & Increase \\
\hline \multicolumn{4}{|c|}{ * Gini coefficient refers to all of Germany for 1992.} \\
\hline \multicolumn{4}{|c|}{ ** Gini coefficient refers to United Kingdom. } \\
\hline \multicolumn{4}{|c|}{$\begin{array}{l}\text { Note: Means were compared using a standard t-test for two independent samples; they were marked "stable" if the test showed } \\
\text { that perceptions were not significantly different at the } 0.05 \text {-level (2-tailed) (see Clauss and Ebner, 1972: } 184 \text { et seq.). A special } \\
\text { weighting was used to correct for different sample sizes in the row labelled "All countries". }\end{array}$} \\
\hline \multicolumn{4}{|c|}{$\begin{array}{l}\text { Source: Author's calculations based on ISSP data sets, Luxembourg Income Study and other sources for Gini coefficients (see } \\
\text { Annex Table 1). }\end{array}$} \\
\hline
\end{tabular}


Moving to the second spell from 1992 to 1999, it can again be observed that people increasingly agree that domestic inequality is too wide (see Table 8 ). The overall average value for an expanded sample, which now includes a total of 16 countries, stood at 1.96 in 1992 and moved to 1.89 in 1999, or further towards the category "strongly agree". The difference between the two years is again significant at the 0.05-level and the disaggregation by country confirms that this was the dominant trend. Perceptions of income differences rose in a total of eight countries, namely Australia, Austria, Philippines and Sweden and four transition countries (Hungary, Poland, Russian Federation and Slovenia). The Russian Federation and Hungary are the two countries with the greatest shifts of -0.35 and -0.36 , respectively, followed by Sweden (-0.24). In contrast, disapproval of inequality remained stable in Bulgaria (where it is at an extraordinarily high level), Canada, New Zealand and Norway.

Only three cases are clear exceptions from the general trend. Respondents from both parts of Germany worried less about inequality (the mean increased by 0.20 in the East and 0.22 in the West), despite an increase in actual inequality between 1992 and 1999. The same happened in the United States (where the mean rose by 0.16). Speculation is possible concerning the reasons for this counter-intuitive development, although it is hard to think of an immediately plausible reason. 
Table 8. Perception of domestic inequality and Gini index, 1992-99

\begin{tabular}{|c|c|c|c|}
\hline & 1992 & 1999 & Trend \\
\hline Australia & 2.38 & 2.24 & Perception up \\
\hline Std. dev. & $(1.02)$ & $(0.89)$ & \\
\hline Gini & 0.308 & 0.318 & Increase \\
\hline Germany West & 1.93 & 2.15 & Perception down \\
\hline Std. dev. & $(0.84)$ & $(0.88)$ & \\
\hline Gini* $^{*}$ & 0.255 & 0.261 & Increase \\
\hline Germany East & 1.43 & 1.63 & Perception down \\
\hline Std. dev. & $(0.57)$ & $(0.66)$ & \\
\hline Gini* $^{*}$ & 0.255 & 0.261 & Increase \\
\hline Great Britain & 1.91 & 1.93 & Stable perception \\
\hline Std. dev. & $(0.92)$ & $(0.84)$ & \\
\hline Gini** & 0.337 & 0.345 & Increase \\
\hline United States & 2.08 & 2.24 & Perception down \\
\hline Std. dev. & $(0.96)$ & $(1.03)$ & \\
\hline Gini & 0.342 & 0.372 & Sharp increase \\
\hline Austria & 1.91 & 1.78 & Perception up \\
\hline Std. dev. & $(0.90)$ & $(0.80)$ & \\
\hline Gini & 0.258 & 0.277 & Increase \\
\hline Hungary & 1.80 & 1.44 & Perception up \\
\hline Std. dev. & $(0.94)$ & $(0.74)$ & \\
\hline Gini & 0.296 & 0.333 & Sharp increase \\
\hline Norway & 2.23 & 2.21 & Stable perception \\
\hline Std. dev. & $(1.02)$ & $(0.98)$ & \\
\hline Gini & 0.233 & 0.238 & Stable \\
\hline Sweden & 2.37 & 2.13 & Perception up \\
\hline Std. dev. & $(1.12)$ & $(1.00)$ & \\
\hline Gini & 0.229 & 0.221 & Decrease \\
\hline Slovenia & 1.74 & 1.64 & Perception up \\
\hline Std. dev. & $(0.92)$ & $(0.79)$ & \\
\hline Gini & 0.226 & 0.240 & Increase \\
\hline Poland & 1.82 & 1.70 & Perception up \\
\hline Std. dev. & $(0.92)$ & $(0.82)$ & \\
\hline Gini & 0.274 & 0.294 & Sharp increase \\
\hline Bulgaria & 1.22 & 1.22 & Stable perception \\
\hline Std. dev. & $(0.62)$ & $(0.60)$ & \\
\hline Gini & 0.311 & 0.346 & Sharp increase \\
\hline Russian Federation & 1.63 & 1.28 & Perception up \\
\hline Std. dev. & $(0.96)$ & $(0.67)$ & \\
\hline Gini & 0.393 & 0.457 & Sharp increase \\
\hline New Zealand & 2.11 & 2.12 & Stable perception \\
\hline
\end{tabular}




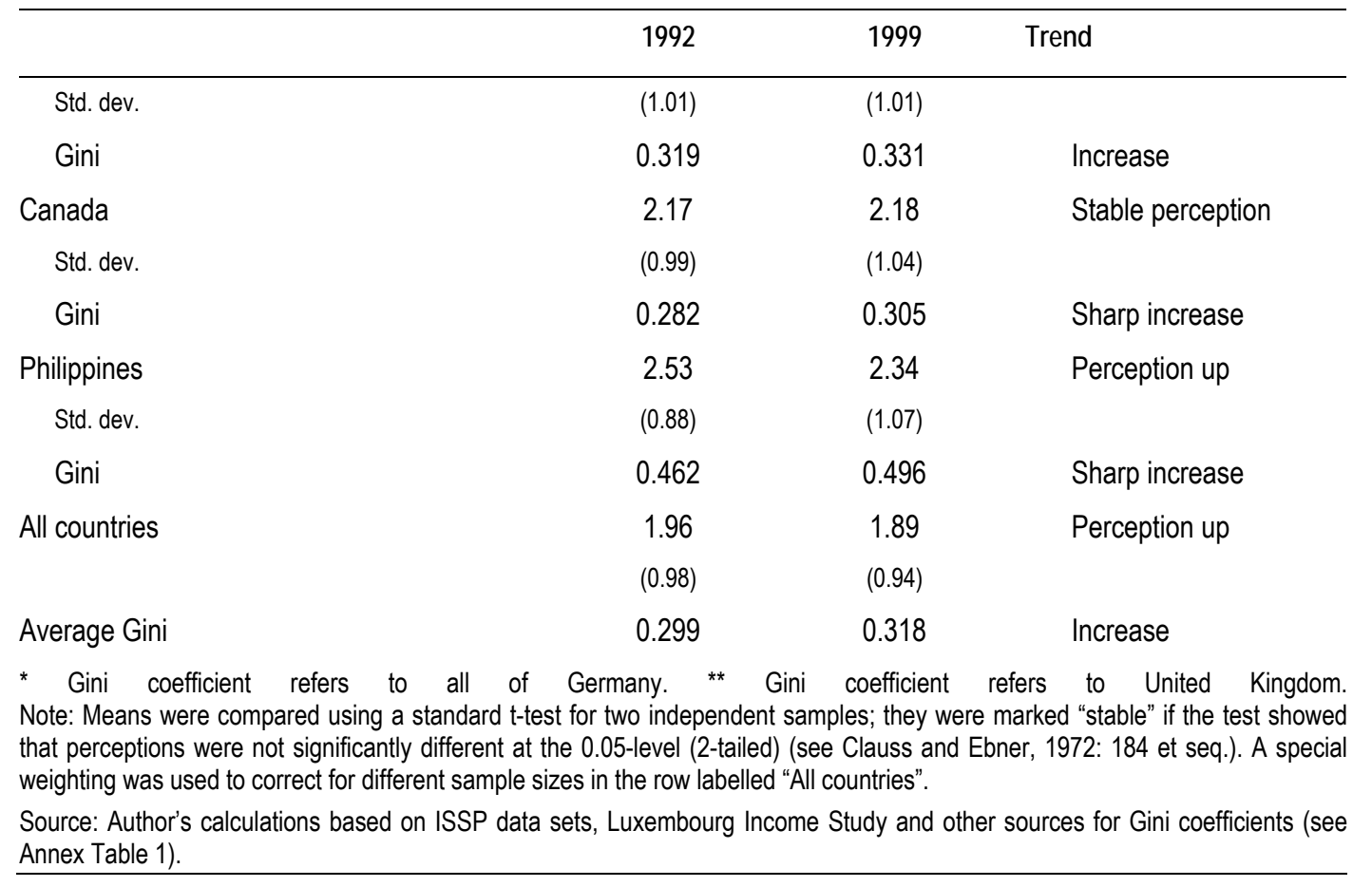

A very clear message nevertheless emerges from the data. People increasingly care about inequality, and they increasingly disagree with the way in which incomes are distributed. This holds true both when comparing the late 1980s with the early 1990s, and the early and late 1990s. ${ }^{7}$ This finding points to increasing pressure on policy-makers around the world to address the issue and to find ways of halting adverse trends in inequality. When advocating free trade, removing labour regulations or designing the other policies that are often associated with globalization, politicians now have less leeway to ignore the social dimensions of these policies than in the early phase of the present wave of globalization. The data therefore support the view that more equitable policies are needed to ensure the political feasibility of globalization, a point that was already made in the initial inventory of issues.

${ }^{7}$ A direct comparison for the seven countries that participated in all three survey rounds confirms this result. 
Table 9. Synopsis of trends in the perception of inequality and in the Gini index

\begin{tabular}{|c|c|c|c|c|c|}
\hline & & \multicolumn{4}{|c|}{ Trends in inequality (Gini index) } \\
\hline \multirow{4}{*}{$\begin{array}{l}\text { Trends in the } \\
\text { perception } \\
\text { of inequality } \\
\text { as being "too } \\
\text { large" }\end{array}$} & & $\begin{array}{c}\text { Decrease } \\
\text { (1 case) }\end{array}$ & $\begin{array}{c}\text { Stable } \\
\text { (3 cases) }\end{array}$ & $\begin{array}{c}\text { Increase } \\
\text { (10 cases) }\end{array}$ & $\begin{array}{c}\text { Sharp increase } \\
\text { (10 cases) }\end{array}$ \\
\hline & $\begin{array}{l}\text { Perception down } \\
\text { (4 cases) }\end{array}$ & & & $\begin{array}{l}\text { Germany West } \\
\text { Germany East }\end{array}$ & \begin{tabular}{|l} 
United States \\
Austria
\end{tabular} \\
\hline & $\begin{array}{l}\text { Stable perception } \\
\text { (6 cases) }\end{array}$ & & $\begin{array}{l}\text { Norway } \\
\text { Poland }\end{array}$ & \begin{tabular}{|l|} 
Great Britain \\
New Zealand
\end{tabular} & \begin{tabular}{|l|} 
Bulgaria \\
Canada
\end{tabular} \\
\hline & $\begin{array}{l}\text { Perception up } \\
\text { (14 cases) }\end{array}$ & Sweden & Italy & $\begin{array}{l}\text { Austria } \\
\text { Australia } \\
\text { Slovenia } \\
\text { Australia } \\
\text { Germany West } \\
\text { United States }\end{array}$ & \begin{tabular}{|l|} 
Hungary \\
Poland \\
Russian \\
Federation \\
Philippines \\
Great Britain \\
Hungary
\end{tabular} \\
\hline $\begin{array}{l}\text { Note: Country r } \\
\text { Source: Author }\end{array}$ & $\begin{array}{l}\text { in italics refer to } 1 \\
\text { slations based on }\end{array}$ & $\begin{array}{l}\text { the remain } \\
\text { ta sets (se }\end{array}$ & $\begin{array}{l}\text { 2/99. } \\
\text { two Tables). }\end{array}$ & & \\
\hline
\end{tabular}

This leads back to the question of how changes in perceptions of inequality are related to actual shifts in income distribution. The respective Gini coefficients are listed alongside the survey data in Tables 7 and 8, and the average figures in both Tables show that inequality indeed increased, both between 1987 and 1992 and between 1992 and 1999. This is compatible with the general picture that the last two and a half decades have seen increasing inequality around the world (see Cornia, 2002). Sweden is the only country in the sample in which inequality decreased (between 1992 and 1999). In a further three countries, the Gini coefficient changed by less than 0.005: in Norway between 1992 and 1999, and in Italy and Poland in the earlier period. Inequality has been marked as "stable" in these cases, as the changes fall within a reasonable margin of error. All other countries experienced increases in excess of 0.005 between the two survey rounds. Moreover, there are ten cases of increases equal to or larger than 0.02 , which have been labelled as "sharp increase".

The independent variable shows very little variation. It is not possible from the sample countries to study the effects of a decrease in inequality, as Sweden is the only country in this category in the sample, although it is very surprising that people in Sweden perceived inequality as being less acceptable after it had actually fallen (see Table 9). As discussed above, the two parts of Germany, the United States (all 1992/99) and Austria (1987/92) also show inconsistent patterns. In these cases, respondents tended to agree less that inequality was too large after it had risen. There is, however, a very large group of 12 cases in which rising inequality has been accompanied by increased awareness of income differences. This includes most transition countries, Australia and Great Britain (only in 1987/92), a well as West Germany and the United States for the earlier period and Austria for the second period. In these three cases, the perception of inequality as being "too large" either increased first and then decreased again (West Germany and United States), or decreased first and then increased (Austria), giving a picture of volatile public opinion. 
Table 10. Correlations between changes in the perception of domestic inequality and changes in the Gini index (Pearson's r)

\begin{tabular}{|c|c|c|c|}
\hline & $\begin{array}{c}\text { Changes in the } \\
\text { Gini index } \\
1987-92\end{array}$ & $\begin{array}{c}\text { Changes in the } \\
\text { Gini index } \\
1992-99\end{array}$ & $\begin{array}{c}\text { Changes in the } \\
\text { Gini index } \\
1987-99\end{array}$ \\
\hline $\begin{array}{l}\text { Changes in the perception of inequality, } \\
1987-92\end{array}$ & $\begin{array}{c}0.408 \\
(0.316) \\
n=8\end{array}$ & & \\
\hline $\begin{array}{l}\text { Changes in the perception of inequality, } \\
1992-99\end{array}$ & & $\begin{array}{c}-0.442 \\
(0.086) \\
n=16\end{array}$ & \\
\hline $\begin{array}{l}\text { Changes in the perception of inequality, } \\
1987-99\end{array}$ & & & $\begin{array}{c}-0.448 \\
(0.314) \\
n=7\end{array}$ \\
\hline \multicolumn{4}{|l|}{ Note: The level of significance is in brackets. } \\
\hline
\end{tabular}

A more formal assessment of the relationship between changes in inequality and in the perception of inequality is found in Table 10. The correlation is insignificant for changes from 1987 to 1992 and from 1987 to 1999 , which is not surprising given the extremely low number of eight and seven cases respectively. For the period from 1987 to 1992, the correlation coefficient actually has an unexpected (positive) sign, which is driven by the counter-intuitive development in a single country, namely Austria. There are many more cases for which data are available for both 1992 and 1999 (16 in total) and the correlation coefficient of $r=-0.442$ would be significant at the 0.10 -level. If this margin of error is accepted, this leads to the conclusion that, for this period, shifts towards greater inequality are associated with an increase in the perception of inequality as being unacceptable. This could be interpreted, as indicated in the alternative hypothesis, as showing that people's values show consistency over time and that they respond with disapproval to rises in inequality. However, given the relatively low level of significance, this should be treated as merely a tentative conclusion. The main finding from this section is that people increasingly condemn inequality and that rises in actual inequality are a likely factor in explaining this.

\section{Perceptions of inequality between countries}

The 1999 round of the ISSP introduced the new topic of international inequality, reflecting the increased prominence it has gained in the public debate. The wording of the statement in the questionnaire was:

Present economic differences between rich and poor countries are too large.

Once again, respondents were asked to record their support on a scale from "strongly agree" (1) to "strongly disagree" (5). The concept referred to here is inequality between countries, which is quite distinct from worldwide inequality between persons. As Milanovic (2000) has shown, inequality between countries accounts for between 75 and 88 per cent of worldwide inequality between persons, with the rest being explained by domestic inequality. 
In cases in which the present paper is concerned with international inequality, as opposed to domestic inequality, the first concept (inequality between countries) is meant and the term "international inequality" is a more intuitive and simpler synonym. Leaving aside the issue of definitions, it is quite striking how many people agree with the view that international inequality is too wide. On average, almost 90 per cent either agree or strongly agree that differences between rich and poor countries are too large, with only 2.9 per cent disagreeing. With an average of 1.69 on the five point scale, the statement that economic differences between rich and poor countries are too large actually finds even more support than the statement relating to domestic inequality (for which the mean stood at 1.85). Once again, at over 90 per cent, agreement is broadest in transition countries, such as Bulgaria, Slovakia and the Russian Federation, as well as in some of the countries that have been classified as "organized market economies", including Austria, France and Spain, and in Brazil and Chile. Surprisingly, at only 74.3 per cent, agreement is considerably lower in the third developing country of the sample, the Philippines. The only value that is even lower (65.3 per cent) is observed in the United States. The other Anglo-Saxon countries also recorded unusually low agreement rates, ranging between 82.3 per cent (Canada) and 83.9 percent (Australia).

This leads to the question as to the extent to which perceptions are driven by norms of social justice, or by the position of the respondent's home country in the global wealth ranking. These two general possibilities can be formulated as two hypotheses:

- The null hypothesis would be that judgements about international inequality are independent of a country's per capita income. People make their judgements according to the same value commitments that they apply to the domestic situation, and the perception of domestic inequality as being too large should, after controlling for the actual extent of domestic inequality, be a good predictor for the perception of international inequality, rather than the per capita income of the respondent's home country.

- The alternative hypothesis would be that people in rich countries, that is those who are on the favourable side of international inequality, do not perceive inequality among countries as a problem, but that people in poorer countries do. Self-interest rather than a consistently applied value of social justice would then govern perceptions of international inequality, and per capita income should be the major explanatory factor.

As often happens in social science, both explanations need not be strictly mutually exclusive. The question is rather the relative strength of the two independent variables suggested above (per capita income versus social justice norms) in respect of each other and how well they can each explain perceptions of international inequality. 
Table 11. Perceptions of inequality between countries

\begin{tabular}{|c|c|c|c|}
\hline & Agreement & Disagreement & Mean \\
\hline Australia & 83.9 & 4.1 & 1.98 \\
\hline Austria & 92.3 & 2.0 & 1.70 \\
\hline Brazil & 95.6 & 3.0 & 1.28 \\
\hline Bulgaria & 97.2 & 1.4 & 1.25 \\
\hline Canada & 82.3 & 6.1 & 1.89 \\
\hline Chile & 93.3 & 3.3 & 1.73 \\
\hline Cyprus & 93.6 & 1.2 & 1.78 \\
\hline Czech Republic & 92.7 & 1.9 & 1.52 \\
\hline France & 91.4 & 2.4 & 1.44 \\
\hline Germany East & 94.6 & 1.8 & 1.67 \\
\hline Germany West & 90.8 & 2.0 & 1.79 \\
\hline Great Britain & 82.4 & 2.7 & 1.96 \\
\hline Hungary & 94.2 & 1.7 & 1.54 \\
\hline Israel & 90.6 & 3.7 & 1.66 \\
\hline Japan & 92.0 & 1.9 & 1.43 \\
\hline Latvia & 89.2 & 2.2 & 1.74 \\
\hline New Zealand & 83.0 & 4.5 & 1.92 \\
\hline Northern Ireland & 83.6 & 3.3 & 1.93 \\
\hline Norway & 90.5 & 2.3 & 1.70 \\
\hline Philippines & 74.3 & 9.3 & 2.14 \\
\hline Poland & 91.6 & 1.4 & 1.74 \\
\hline Portugal & 94.9 & 1.6 & 1.26 \\
\hline Russian Federation & 93.1 & 2.7 & 1.46 \\
\hline Slovakia & 96.2 & 0.5 & 1.33 \\
\hline Slovenia & 93.7 & 2.0 & 1.74 \\
\hline Spain & 94.1 & 2.1 & 1.69 \\
\hline Sweden & 82.8 & 2.8 & 1.84 \\
\hline United States & 65.3 & 7.2 & 2.22 \\
\hline Average & 89.3 & 2.9 & 1.69 \\
\hline
\end{tabular}


As in the previous section, a graphical presentation of the data can help in gaining a preliminary impression. Figure 3 plots per capita income in PPP\$ (purchasing power parity) against perceptions of international inequality (or inequality between countries). The general pattern appears to be that, as income rises, agreement with the statement that international inequality is too large becomes weaker. The United States, the richest country in the sample, and Bulgaria, the second poorest country, seem to mark the end points of an imagined rising regression line. Although some countries, such as the poor Philippines or rich France and Japan, are positioned apart from the main cluster, the relationship between income and views on international inequality seems on the whole to be quite robust. Regression (9) in Table 12 constitutes a formal test in which the simple specification of per capita income indeed turns out to be a significant explanatory variable accounting for 12.8 per cent of the overall variation of the dependent variable (as evident from the adjusted $\mathrm{R}^{2}$ ). As may be concluded from the regression coefficients, the mean for agreement moves 0.121 steps towards "disagree" on the five point scale with every 10,000 PPP\$ rise in per capita income.

\section{Figure 3. Per capita income and the perception of international inequality}

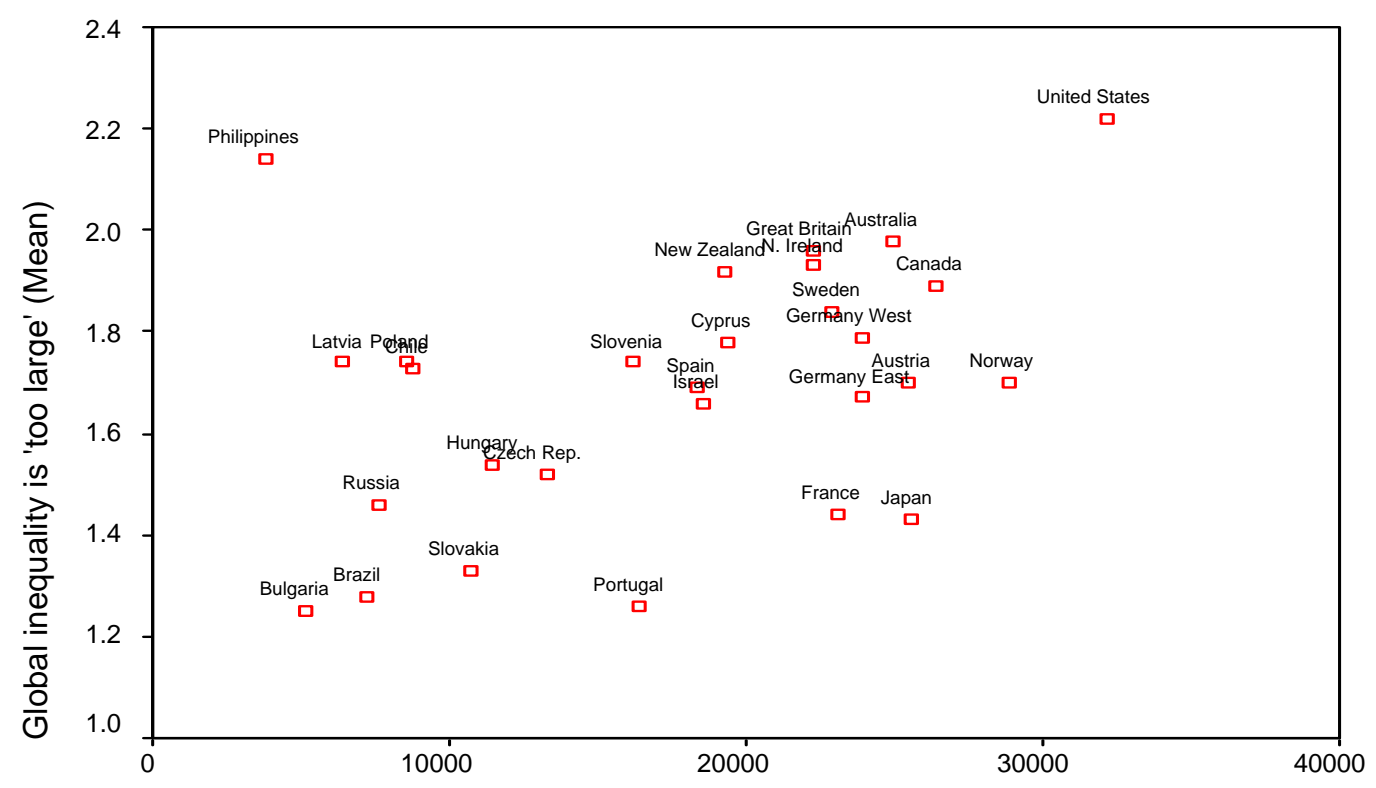

Per capita GDP in PPP\$ (1999)

Even though this might seem to lend strong support to the alternative hypothesis, such a conclusion would be premature. As has been shown in the previous section, the Anglo-Saxon countries that are clustered in the upper right part of Figure 3 are not only rich, but also particularly tolerant towards inequality, and it might be this, rather than their high income levels, that contributes to the relatively favourable assessment of differences between poor and rich countries. The same argument could apply to the transition countries, which not only have a very high prevalence of egalitarian norms, but are also poor by the standards of the sample. 
To test this possibility, regression (10) in Table 12 introduces the perception of domestic inequality into the equation and regression (11) adds the Gini index as a further control variable. Both aggregate level regressions produce the same result, which is quite striking and unexpected in its clarity. Income level loses its significance by any standards and perceptions of domestic inequality take over as the sole explanatory variable. Average perceptions of domestic and international inequality actually shadow each other quite closely. A step from "agree" towards "strongly agree" with the statement that domestic inequality is too large leads to a step of 0.645 (regression 10) or 0.626 (regression 11) in the same direction when people are asked to comment on international inequality. With 64 per cent of the overall variance explained, attitudes towards domestic inequality are an extremely good predictor of attitudes towards international inequality. When norms are controlled for as they emerge from perceptions of domestic inequality, it is possible to reject the idea that judgements of global income distribution are driven by or even related to the income level of respondents in their own country.

Table 12. Tolerance of international inequality and per capita income, aggregate level regression

\begin{tabular}{|l|c|c|c|c|c|c|c|c|c|c|}
\hline & & $\mathbf{( 9 )}$ & & & $(\mathbf{1 0})$ & & & $(\mathbf{1 1})$ & \\
\hline & Coef. (b) & Std. err & Sign. & Coef. (b) & Std. err. & Sign. & Coef.(b) & Std. err. & Sign. \\
\hline Constant & 1.490 & 0.109 & 0.000 & 0.636 & 0.160 & 0.001 & 0.520 & 0.208 & 0.021 \\
\hline $\begin{array}{l}\text { Per capita income } \\
\text { (in 10,000 PPP\$) }\end{array}$ & 0.121 & 0.056 & 0.041 & -0.055 & 0.047 & 0.251 & -0.030 & 0.055 & 0.586 \\
\hline $\begin{array}{l}\text { Domestic inequality } \\
\text { is "too large" }\end{array}$ & & & & 0.645 & 0.109 & 0.000 & 0.626 & 0.112 & 0.000 \\
\hline Gini index & & & & & & & 0.323 & 0.369 & 0.390 \\
\hline$R^{2}$ (adjusted) & 0.128 & & 0.041 & 0.640 & & 0.000 & 0.636 & & 0.000 \\
\hline
\end{tabular}

Note: Dependent variable is "Present economic differences between rich and poor countries are too large". Aggregate level data set, number of valid observations $=26$ (excluding Portugal and Cyprus).

Source: Author's calculations based on ISSP data sets.

As before, it would appear to be worthwhile to counter-check these results by making use of the individual level data set, as in Table 13. Owing to the large number of over 30,000 observations, whatever variable is entered in regressions (12) to (14) turns out to be significant. The issue is therefore to assess how powerful the various explanatory variables are in practice. A first indication is given by the adjusted $\mathrm{R}^{2}$. When entered on its own, per capita income can only explain 1.6 per cent of the overall variance in perceptions of international inequality. When perceptions of domestic inequality and the Gini index are subsequently entered, $\mathrm{R}^{2}$ rises to around 13 per cent, demonstrating that these variables are far better suited than per capita income to explaining tolerance of international inequality. 
Table 13. Tolerance of international inequality and per capita income, individual level regression

\begin{tabular}{|l|c|c|c|c|c|c|c|c|c|}
\hline & & $\mathbf{( 1 2 )}$ & & & $\mathbf{( 1 3 )}$ & & & $\mathbf{( 1 4 )}$ & \\
\hline & Coef. (b) & Std err. & Sign. & Coef. (b) & Std. err. & Sign. & Coef. (b) & Std. err. & Sign. \\
\hline Constant & 1.494 & 0.010 & 0.000 & 1.114 & 0.012 & 0.000 & 0.869 & 0.025 & 0.000 \\
\hline $\begin{array}{l}\text { Income per capita } \\
\text { (in 10,000 PPP\$) }\end{array}$ & 0.119 & 0.005 & 0.000 & 0.041 & 0.005 & 0.000 & 0.077 & 0.006 & 0.000 \\
\hline $\begin{array}{l}\text { Domestic inequality } \\
\text { is "too large" }\end{array}$ & & & & 0.285 & 0.005 & 0.000 & 0.282 & 0.005 & 0.000 \\
\hline Gini index & & & & & & & 0.569 & 0.050 & 0.000 \\
\hline $\mathrm{R}^{2}$ (adjusted) & 0.016 & & 0.000 & 0.129 & & 0.000 & 0.133 & & 0.000 \\
\hline
\end{tabular}

Note: Dependent variable is "Present economic differences between rich and poor countries are too large". Individual level data set, number of valid observations $\geq 30,000$ (excluding Portugal and Cyprus).

Source: Author's calculations based on ISSP data sets.

The regression coefficients, which provide information on the gradient of the regression line, can shed further light on the influence of the explanatory variables that are used here. The positive trend of the income variable shows that tolerance of international inequality rises with increasing income, and this effect remains intact even when other variables are introduced. However, the influence of per capita income is relatively small. It would require an hypothetical increase in per capita GDP of 244,000 PPP\$ (regression 13) or 130,000 PPP\$ (regression 14) to shift agreement with the statement that economic differences between rich and poor countries are too large from "agree" towards "neither agree nor disagree". This is equivalent (in the lowest case) to multiplying current Japanese or Australian incomes by six. Another way of looking at the regression coefficients is to compare them directly with each other. In regression (13), it would be necessary to increase per capita income by 69,500 PPP\$ to achieve the same effect as a step of one in the perception of domestic inequality, and in regression (14) the sum still stands at 36,600 PPP\$. These are of course extraordinarily large sums, pointing once again to the minor influence exercised by per capita income.

The overall finding of this section can therefore be summarized in two points. First, as indicated in the description at the beginning of this chapter, an overwhelming majority of almost 90 per cent hold the view that economic differences between rich and poor countries are too large. Despite the fact that most people are less directly confronted by international inequality than domestic inequality, there is greater agreement with the statement relating to international than domestic inequality. Although there are some differences between respondents from different countries, this represents a broad consensus around the world that the global income gap is unacceptable. Second, the judgements that people make about the gap between rich and poor countries follow the same general norms of distributive social justice as they apply to the domestic context. When the beliefs that people hold about justice are taken into account, perceptions of international inequality become largely independent of the income level in their country of residence. There is therefore no simple dichotomy between people from rich and poor countries. 
This is a very encouraging finding for anyone who wants to modify current patterns of international inequality. Public views seem to be supportive of such efforts. However, it could be argued that it is easy to agree that the current state of global income distribution is unfair, even for persons who reside in rich countries, but that it is quite a different matter for them to be willing to share some of their wealth with the have-nots. This question is addressed below.

\section{Support for redistributive government interventions}

Like other forms of public intervention, the idea that governments should intervene in market outcomes and redistribute incomes according to social criteria has dramatically lost ground in recent decades. While publications such as Redistribution with growth by Chenery et al. (1974) mirrored the prominence of the issue in the 1970s, there has been little favourable mention of redistribution during the 1980s and early 1990s. Economists have tended to emphasize that redistribution undermines incentives and is therefore likely to harm long-term growth (see, for example, Alesina and Rodrik, 1994). It is only recently that potential efficiency gains through redistribution have been discussed in greater detail. Aghion et al. conclude from their summary of the ongoing debate that "when capital markets are imperfect, there is scope for redistributive policies which are also growth enhancing" (1999: 1656). For example, redistribution could enable those who lack capital (and access to it) to undertake highly profitable investments, and could therefore be instrumental in allocating capital more efficiently than the market.

While efficiency gains or losses are one important aspect of redistribution, Boadway and Keen (2000) point to two further rationales for redistribution. People could demand redistribution for broadly altruist reasons, based on an ethical or religious imperative for pursuing social justice. On the other hand, they could also demand redistribution out of pure self-interest when they expect net gains for themselves. As Boadway and Keen rightly emphasize, it is not always possible to disentangle these different motivations, but the ISSP data may still provide some interesting insights. Does a person's assessment that differences in income are too large lead her or him to support redistribution? Or is there a clear distinction between those who are the likely winners of redistribution and those who would have to pay for it, regardless of their views on inequality?

Section 3.2 endeavours to explain support for redistribution by using two variables to operationalize these factors: agreement with the statement that inequality is too large (as already indicated in section 1 above); and subjective social class. However tentative the answers are bound to be, they may still provide some insights about notions of solidarity within society and the extent to which the better-off are prepared to share some of their wealth. The same approach can, of course, also be applied to the global context. Whereas people in poor countries would be expected to be extremely supportive of any transfer of resources away from the rich and towards the poor countries, this is less clear for those who live in the rich countries. Do they fiercely oppose such plans, or is there some altruism on their part that makes them support international redistribution? This is among the questions raised in sections 3.3 and 3.4, which deal with international redistribution. 
Before turning to the question of how support for redistribution can best be explained, it is worth examining how widespread support is for the idea that governments have an obligation to reduce income differences and how this has changed over time. To measure this, the ISSP module on social inequality asked respondents to comment on the following statement:

It is the responsibility of the government to reduce differences in income between people with high incomes and those with low incomes.

again using five response categories ranging from "strongly agree" (1) to "strongly disagree" (5). At just over two-thirds, the opinion that governments indeed have such a responsibility is quite widespread. Only a minority of 16.5 per cent disagree outright, and roughly 15 per cent are undecided (see Table 14).

Once again, there are quite remarkable differences between countries. In a number of countries, a majority of 80 per cent or more support government redistribution. Many of these countries are in Central and Eastern Europe (Bulgaria, Hungary, Poland, Russian Federation and Slovenia), although countries such as Brazil, Israel, Italy and Portugal are to be found alongside them. At the other extreme, support rates of lower than 50 per cent are found in Switzerland and the non-European Anglo-Saxon countries (Australia, Canada, New Zealand and the United States). However, even in these countries, more respondents support domestic redistribution than oppose it. The only exception is the United States, where 39.3 per cent are opposed to redistribution and only 35.3 speak out in favour of it. Another way of reading the data is to look at the mean responses. A figure below 2.0 would mean that average responses are between "strongly agree" and "agree", and therefore firmly supportive of redistribution. Such response rates are found in 11 of the 31 countries included in the sample, while in a further four (Chile, Czech Republic, East Germany and Latvia) they are just above 2.0. The remaining countries range between "agree" and "neither agree nor disagree", and once again the United States is the only country in which people tend to disagree that government should redistribute incomes (with a mean response in excess of 3.0).

It is again possible from the data to track the manner in which public support for redistribution has evolved for a number of countries since the late 1980s. Two conflicting expectations might be assumed to exist. On the one hand, it could be argued that the emphasis in the public debate on cutting back the State's involvement in the economy reflects frustration with the welfare state, high tax rates and over-regulation. On the other hand, it has been demonstrated earlier that inequality rose in virtually all the countries included in the ISSP sample, and so the necessity for State action to stop or reverse this trend could have become even more obvious for many people over time. 
Tables 15 and 16 present the available data and the relevant Gini coefficients. As in section 1 , survey responses have been subjected to a standard $t$-test for two independent samples to exclude differences that are within the normal margin of error. No significant change in the demand for redistribution could be detected in four countries between 1987 and 1992 (Australia, Great Britain, Hungary and Italy), while demand fell in Austria and increased in Poland, West Germany and the United States. The average across all the countries covered by the survey for both years changed slightly, but significantly, from 2.40 in 1987 to 2.36 in 1992, pointing to a minor increase in public support for redistribution. 
Table 14. Support for domestic redistribution, 1999 (or latest available year)

\begin{tabular}{|c|c|c|c|}
\hline & Agreement & Disagreement & Mean \\
\hline Australia & 49.7 & 28.9 & 2.74 \\
\hline Austria & 72.5 & 13.9 & 2.17 \\
\hline Brazil & 91.0 & 6.0 & 1.48 \\
\hline Bulgaria & 85.0 & 8.4 & 1.69 \\
\hline Canada & 47.5 & 33.9 & 2.81 \\
\hline Chile & 78.2 & 9.3 & 2.05 \\
\hline Cyprus & 57.3 & 19.4 & 2.50 \\
\hline Czech Republic & 71.9 & 16.6 & 2.07 \\
\hline France & 67.5 & 17.4 & 2.18 \\
\hline Germany East & 76.2 & 9.5 & 2.08 \\
\hline Germany West & 52.4 & 29.2 & 2.71 \\
\hline Great Britain & 68.7 & 15.1 & 2.30 \\
\hline Hungary & 80.1 & 7.6 & 1.82 \\
\hline Israel & 80.9 & 10.7 & 1.88 \\
\hline Italy (1992) & 80.1 & 9.4 & 1.91 \\
\hline Japan & 52.6 & 20.8 & 2.54 \\
\hline Latvia & 78.7 & 11.8 & 2.01 \\
\hline Netherlands (1987) & 65.1 & 13.7 & 2.48 \\
\hline New Zealand & 49.4 & 34.4 & 2.75 \\
\hline Northern Ireland & 66.3 & 14.2 & 2.31 \\
\hline Norway & 61.9 & 19.7 & 2.45 \\
\hline Philippines & 58.6 & 19.1 & 2.48 \\
\hline Poland & 84.9 & 6.4 & 1.87 \\
\hline Portugal & 89.9 & 6.3 & 1.49 \\
\hline Russian Federation & 86.1 & 6.6 & 1.60 \\
\hline Slovakia & 74.5 & 10.1 & 1.97 \\
\hline Slovenia & 84.8 & 6.7 & 1.82 \\
\hline Spain & 79.3 & 8.4 & 1.99 \\
\hline Sweden & 59.5 & 18.4 & 2.41 \\
\hline Switzerland (1987) & 42.7 & 39.5 & 2.96 \\
\hline United States & 35.3 & 39.3 & 3.08 \\
\hline Average & 68.7 & 16.5 & 2.21 \\
\hline
\end{tabular}

Note: Respondents were asked to comment on the following statement: "It is the responsibility of the government to reduce the differences in income between people with high incomes and those with low incomes". The answer categories given were "strongly agree" (1), "agree" (2), "neither agree nor disagree" (3), "disagree" (4) and "strongly disagree" (5). For this Table, categories (1) and (2) were collapsed into "agreement" and (4) and (5) into "disagreement". "Mean" is the simple average value for all answers from a given country. Weighted by weight 1 .

Source: Author's calculations based on ISSP data sets. 
Table 15. Support for domestic redistribution, mean responses, 1987-92

\begin{tabular}{|c|c|c|c|}
\hline & 1987 & 1992 & Trend \\
\hline Australia & 2.88 & 2.93 & No change \\
\hline Std. dev. & $(1.12)$ & $(1.15)$ & \\
\hline Gini & 0.298 & 0.308 & Increase \\
\hline Germany West & 2.53 & 2.40 & Support up \\
\hline Std. dev. & $(1.19)$ & $(1.12)$ & \\
\hline Gini* & 0.248 & 0.255 & Increase \\
\hline Great Britain & 2.40 & 2.31 & No change \\
\hline Std. dev. & $(1.12)$ & $(1.13)$ & \\
\hline Gini** & 0.310 & 0.337 & Sharp increase \\
\hline United States & 3.23 & 3.05 & Support up \\
\hline Std. dev. & $(1.14)$ & $(1.21)$ & \\
\hline Gini & 0.335 & 0.342 & Increase \\
\hline Austria & 1.99 & 2.25 & Support down \\
\hline Std. dev. & $(1.00)$ & $(1.12)$ & \\
\hline Gini & 0.227 & 0.258 & Sharp increase \\
\hline Hungary & 1.99 & 2.04 & No change \\
\hline Std. dev. & $(0.95)$ & $(1.01)$ & \\
\hline Gini & 0.273 & 0.296 & Sharp increase \\
\hline Poland & 2.17 & 2.07 & Support up \\
\hline Std. dev. & $(1.21)$ & $(1.01)$ & \\
\hline Gini & 0.272 & 0.274 & Stable \\
\hline Italy & 1.94 & 1.91 & No change \\
\hline Std. dev. & $(0.94)$ & $(0.98)$ & \\
\hline Gini & 0.303 & 0.302 & Stable \\
\hline \multirow[t]{2}{*}{ All countries } & 2.40 & 2.36 & Support up \\
\hline & $(1.17)$ & $(1.16)$ & \\
\hline Average Gini & 0.283 & 0.297 & Increase \\
\hline \multicolumn{4}{|c|}{${ }^{*}$ Gini coefficient refers to all of Germany. ${ }^{* *}$ Gini coefficient refers to the United Kingdom. } \\
\hline \multicolumn{4}{|c|}{$\begin{array}{l}\text { Note: Means have been compared using a standard t-test for two independent samples; they have been marked "stable" if the tes } \\
\text { showed that perceptions were not significantly different at the } 0.05 \text {-level (2-tailed) (see Clauss and Ebner, 1972: } 184 \text { et seq. } \\
\text { A special weighting is used to correct for different sample sizes in the row labelled "All countries". }\end{array}$} \\
\hline
\end{tabular}


Table 16. Support for domestic redistribution, mean responses, 1992-99

\begin{tabular}{|c|c|c|c|}
\hline & 1992 & 1999 & Trend \\
\hline Australia & 2.93 & 2.74 & Support up \\
\hline Std. dev. & $(1.15)$ & $(1.06)$ & \\
\hline Gini & 0.308 & 0.318 & Increase \\
\hline Germany West & 2.40 & 2.71 & Support down \\
\hline Std. dev. & $(1.12)$ & $(1.18)$ & \\
\hline Gini* & 0.255 & 0.261 & Increase \\
\hline Germany East & 1.74 & 2.08 & Support down \\
\hline Std. dev. & $(0.80)$ & $(0.93)$ & \\
\hline Gini* & 0.255 & 0.261 & Increase \\
\hline Great Britain & 2.31 & 2.30 & No change \\
\hline Std. dev. & (1.13) & $(0.99)$ & \\
\hline Gini** & 0.337 & 0.345 & Increase \\
\hline United States & 3.05 & 3.08 & No change \\
\hline Std. dev. & $(1.21)$ & $(1.23)$ & \\
\hline Gini & 0.342 & 0.372 & Sharp increase \\
\hline Austria & 2.25 & 2.17 & No change \\
\hline Std. dev. & (1.12) & $(1.10)$ & \\
\hline Gini & 0.258 & 0.277 & Increase \\
\hline Hungary & 2.04 & 1.82 & Support up \\
\hline Std. dev. & $(1.01)$ & $(0.99)$ & \\
\hline Gini & 0.296 & 0.333 & Sharp increase \\
\hline Norway & 2.51 & 2.45 & No change \\
\hline Std. dev. & $(1.14)$ & $(1.11)$ & \\
\hline Gini & 0.233 & 0.238 & Stable \\
\hline Sweden & 2.69 & 2.41 & Support up \\
\hline Std. dev. & $(1.23)$ & $(1.15)$ & \\
\hline Gini & 0.229 & 0.221 & Decrease \\
\hline Slovenia & 2.01 & 1.82 & Support up \\
\hline Std. dev. & $(0.96)$ & $(0.88)$ & \\
\hline Gini & 0.226 & 0.240 & Increase \\
\hline Poland & 2.07 & 1.87 & Support up \\
\hline Std. dev. & $(1.01)$ & $(0.86)$ & \\
\hline Gini & 0.274 & 0.294 & Sharp increase \\
\hline Bulgaria & 1.76 & 1.69 & No change \\
\hline Std. dev. & $(1.20)$ & $(1.04)$ & \\
\hline Gini & 0.311 & 0.346 & Sharp increase \\
\hline Russian Federation & 2.23 & 1.60 & Support up \\
\hline Std. dev. & $(1.32)$ & $(0.95)$ & \\
\hline Gini & 0.393 & 0.457 & Sharp increase \\
\hline
\end{tabular}




\begin{tabular}{lccc}
\hline & $\mathbf{1 9 9 2}$ & $\mathbf{1 9 9 9}$ & Trend \\
\hline New Zealand & 2.69 & 2.75 & No change \\
Std. dev. & $(1.21)$ & $(1.30)$ & \\
Gini & 0.319 & 0.331 & Increase \\
Canada & 2.76 & 2.81 & No change \\
Std. dev. & $(1.24)$ & $(1.26)$ & \\
Gini & 0.282 & 0.305 & Sharp increase \\
Philippines & 2.50 & 2.48 & No change \\
Std. dev. & $(0.87)$ & $(1.07)$ & \\
Gini & 0.462 & 0.496 & Sharp increase \\
Average all countries & 2.37 & 2.29 & Support up \\
& $(1.17)$ & $(1.16)$ & \\
Average Gini & 0.299 & 0.318 & Increase \\
\hline
\end{tabular}

This trend is stronger if the results for 1992 to 1999 are compared for the 16 countries covered by both rounds of the survey. While average support for redistribution stood at 2.37 in 1992, it reached 2.29 in 1999. In part, this reflects particularly large increases in support for redistribution in transition countries such as Hungary, Poland, Russian Federation and Slovenia, which also experienced very adverse trends in inequality during the 1990s. But agreement with the statement that governments should reduce differences in incomes also rose in Australia and Sweden, while remaining stable in the remaining countries, except for Germany, where it fell in both the Western and Eastern parts of the country. These trends would appear to contradict the argument advanced above that a shift in the public and academic debate towards reducing government involvement can be seen as a reflection of growing public frustration with the welfare state and increasing opposition to redistribution. Instead, there seems to be a growing gap between calls to cut back State redistribution and increased public support for redistribution policies.

Table 17. Synopsis of trends in support for redistribution and in the Gini index

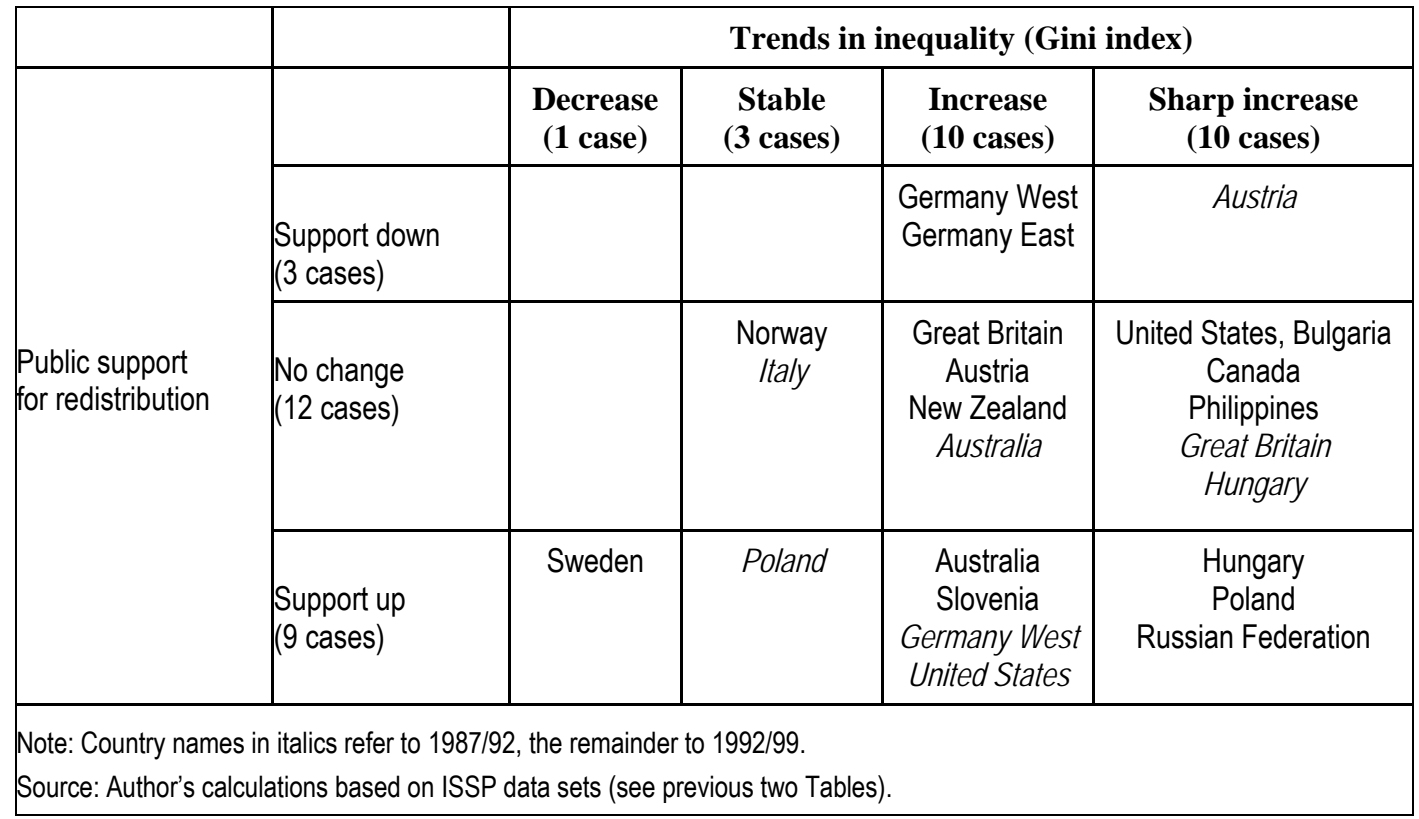


Table 17 once again summarizes these trends and relates them to developments in inequality. East and West Germany (between 1992 and 1999) and Austria (from 1987 to 1992) are the only three cases in which public support for redistribution fell, ${ }^{8}$ and this occurred despite an increase in inequality. Sweden also stands out as a special case. Inequality actually decreased in Sweden, but support for government redistribution nevertheless grew between the survey rounds. However, there are quite a number of cases which support the hypothesis that growing inequality is likely to give rise to increased support for redistribution. In West Germany and the United States (from 1987 to 1992), increases in inequality occurred alongside growing support for redistribution, and the same is true for Australia, Hungary, Poland, Russian Federation and Slovenia for the period between 1992 and 1999 .

A more formal test of this relationship is found in Table 18. While (in part due to the small number of cases) no significant correlation can be established between trends in inequality and support for redistribution between 1987 and 1992 and between 1987 and 1999, the correlation coefficient is quite high $(r=-0.527)$ and significant for the period from 1992 to 1999. The negative indicator confirms that, as the Gini index rose, public support for the statement "It is the responsibility of the government to reduce differences in income between people with high incomes and those with low incomes" shifted increasingly towards "strongly agree". This indicates that people expect their governments to act when adverse shifts occur in inequality.

Table 18. Correlations between changes in support for redistribution and changes in the Gini index (Pearson's $r$ )

\begin{tabular}{|l|c|c|c|}
\hline & $\begin{array}{c}\text { Changes in the } \\
\text { Gini index, } \\
1987-92\end{array}$ & $\begin{array}{c}\text { Changes in the } \\
\text { Gini index, } \\
1992-99\end{array}$ & $\begin{array}{c}\text { Changes in the } \\
\text { Gini index, } \\
1987-99\end{array}$ \\
\hline $\begin{array}{l}\text { Changes in support for } \\
\text { redistribution, 1987-92 }\end{array}$ & $\begin{array}{c}0.100 \\
(0.813) \\
\mathrm{n}=8\end{array}$ & & \\
\hline Changes in support for & & -0.527 & \\
redistribution, 1992-99 & & $(0.036)$ & \\
\hline Changes in support for & & & -0.448 \\
redistribution, 1987-99 & & & $(0.314)$ \\
& & & $\mathrm{n}=7$ \\
\hline Note: The level of significance is in brackets. \\
Source: Author's calculations based on ISSP data sets.
\end{tabular}

${ }^{8}$ In the case of Germany, this may be related to the change of government in 1998, when the centre left coalition of Chancellor Schröder took power after running a campaign that placed heavy emphasis on social justice, and a possible counter-reaction by those citizens who feared that interventionism would now go too far. 
Progressive taxes are among the many instruments that governments can use to reduce differences between high and low incomes. The ISSP module on social inequality included an item to measure public views on such taxes, and the responses can be used to countercheck the validity of the data presented above. After all, it is entirely possible that people support the general goal of bridging income gaps, but that their support fades once it comes to policy proposals that might negatively affect their personal income situation.

The wording of the question was as follows:

Do you think people with high incomes should pay a larger share of their income in taxes than those with low incomes, the same share, or a smaller share.

The answer categories were "much larger share" (1), "larger" (2), "the same share" (3), "smaller" (4) and "much smaller share" (5). Even though this wording appears to be well chosen, the concept of progressive taxes itself requires some level of abstraction. Respondents need to distinguish between "share" and "amount" and to realize that rich people would pay far higher taxes in absolute terms even if they paid the same share that is paid by poorer people. Unfortunately, it is hard to exclude the possibility that respondents who believe that rich people should pay more taxes (in the sense of a higher sum) are led to answer that rich people should pay a "larger share" of their income when confronted with the above question in an interview situation. 
Table 19. Support for progressive taxes, 1999

\begin{tabular}{|c|c|c|c|}
\hline $\begin{array}{l}\text { People with high incomes should } \\
\text { pay as tax }\end{array}$ & $\begin{array}{l}\text { a larger or a much } \\
\text { larger share of their } \\
\text { income }\end{array}$ & $\begin{array}{l}\text { a smaller or a } \\
\text { much smaller } \\
\text { share of their } \\
\text { income }\end{array}$ & Mean \\
\hline Australia & 77.9 & 0.9 & 2.03 \\
\hline Austria & 84.9 & 0.4 & 1.86 \\
\hline Brazil & 84.6 & 1.5 & 1.67 \\
\hline Bulgaria & 92.7 & 1.3 & 1.44 \\
\hline Canada & 69.2 & 2.0 & 2.14 \\
\hline Chile & 80.2 & 5.1 & 1.72 \\
\hline Cyprus & 77.7 & 0.9 & 1.99 \\
\hline Czech Republic & 77.9 & 0.9 & 1.95 \\
\hline France & 73.3 & 5.9 & 2.08 \\
\hline Germany East & 83.0 & 1.6 & 1.90 \\
\hline Germany West & 78.7 & 1.4 & 2.01 \\
\hline Great Britain & 78.7 & 0.3 & 2.00 \\
\hline Hungary & 84.0 & 1.9 & 1.88 \\
\hline Israel & 76.9 & 2.8 & 1.98 \\
\hline Japan & 91.0 & 3.2 & 1.69 \\
\hline Latvia & 72.7 & 1.0 & 2.04 \\
\hline New Zealand & 62.5 & 0.9 & 2.23 \\
\hline Northern Ireland & 72.4 & 0.8 & 2.03 \\
\hline Norway & 76.0 & 1.4 & 2.06 \\
\hline Philippines & 76.5 & 6.1 & 1.89 \\
\hline Poland & 85.2 & 2.5 & 1.79 \\
\hline Portugal & 88.3 & 0.8 & 1.71 \\
\hline Russian Federation & 90.5 & 0.4 & 1.47 \\
\hline Slovakia & 80.7 & 0.2 & 1.84 \\
\hline Slovenia & 87.7 & 1.2 & 1.80 \\
\hline Spain & 84.6 & 0.8 & 1.92 \\
\hline Sweden & 76.3 & 1.3 & 2.09 \\
\hline United States & 65.0 & 2.3 & 2.16 \\
\hline Average & 79.6 & 1.8 & 1.91 \\
\hline \multicolumn{4}{|c|}{$\begin{array}{l}\text { Note: Respondents were asked to answer the following question: "Do you think people with high incomes should pay a larger } \\
\text { share of their income in taxes than those with low incomes, the same share, or a smaller share". The answer categories were: } \\
\text { "much larger share" (1), "larger" (2), "the same share" (3), "smaller" (4) and "much smaller share" (5). For this Table, categories (1 } \\
\text { and (2) were collapsed into "larger or much larger share" and (4) and (5) into "smaller or much smaller share". "Mean" is the simpl } \\
\text { average value for all answers from a given country. Weighted by weight1. } \\
\text { Source: Author's calculations based on ISSP data sets. }\end{array}$} \\
\hline
\end{tabular}


One finding that reinforces these doubts is that support for redistribution and progressive taxes is not as closely correlated as might be expected. At a Pearson's $r=0.193$ (significant on the 0.00 -level), the relationship is only modestly strong at the individual level, indicating that the question may be somewhat ambiguous. Some respondents might understand the question differently from others, and their answers may therefore diverge. However, at the country level these possible misunderstandings seem to cancel each other out quite well. Country means are quite similar to those when people are asked to comment on redistribution (see Table 19). With a highly significant correlation of Pearson's $r=0.728$, mean answers are almost perfectly correlated at the aggregate level. Countries that stand out for their high support of redistribution also record the highest approval rates for progressive taxes. This applies to Brazil, Bulgaria, Hungary, Poland, Portugal, Russian Federation and Slovenia, where at least 80 per cent of all respondents said that people with high incomes should pay a larger or much larger share of their incomes in taxes. Canada, New Zealand and the United States are again the countries where support is lowest, but even in these cases two-thirds of respondents agree that recipients of high incomes should pay higher tax rates. On the aggregate level, both instruments therefore apparently measure very similar things.

\section{2}

\section{Explaining support for domestic redistribution: the role of self-interest and altruism}

This leads to the question of how support for redistribution can best be explained, and how differences between countries can be accounted for. As indicated above, in addition to efficiency considerations, two principal factors could explain support for domestic redistribution:

- Normative considerations. Ethical and religious norms could be a powerful reason for people to call upon the State to intervene in the distribution of income and narrow the gap between the rich and the poor so as to make society more equitable. Following Sen's argument outlined above, such distributive concepts of social justice also determine the assessment of current economic differences (together with the actual situation to which they are compared). Those who believe that domestic inequality is too wide in their country should therefore also support redistribution.

- Self-interest. The material gains of redistribution could lead net beneficiaries to support redistribution, while the recipients of high incomes are, by their very nature, net losers from redistribution and should therefore oppose it. Based on the assumption that those in the middle of the distribution are ill-informed as to whether they would lose or gain from redistribution, they should take a moderate position. The self-interest theorem then leads to the expectation that the higher a person's position in the social hierarchy, the greater her or his opposition to redistribution, while the lower her or his stratum, the greater her or his support for redistribution.

While most people would intuitively agree that a mix of both motivations (and possibly also of efficiency considerations) lead people to support or oppose redistribution, one large body of literature has exclusively concentrated on the self-interest theorem. One of the most influential works in this field is an article by Meltzer and Richard (1981), who spelt out "a rational theory of the size of government". Their theory is based on the median voter 
hypothesis, an idea that is central to the entire rational choice tradition (see Downs, 1957). Their starting assumption is that "[u]nder majority rule, the voter with median income is decisive [...] [and] chooses the tax rate that maximizes his utility" (Meltzer and Richard, 1981: 920). In a simplified scenario in which the two sole activities of governments are taxation and the redistribution of these taxes, the lower the median voters' income relative to overall income, the stronger the preference for redistribution (and therefore also for higher taxes). This leads to the conclusion that "[w]hen the mean income rises relative to the income of the decisive voter, taxes rise, and vice versa" (ibid.: 924). The ratio of mean to median income is, of course, just another expression for inequality and, based on the assumption that income follows a lognormal distribution, is monotonically related to the Gini index. ${ }^{9}$ It is not therefore surprising that new growth theory has explored the possibility that higher demand for redistribution is one of the factors that links high inequality to lower growth (see Clarke, 1992; Alesina and Rodrik, 1994; for a summary see Aghion et al., 1999).

In summary, the hypothesis put forward by this body of literature is that high inequality leads to a high demand for redistribution. This hypothesis is readily testable with the data used in this paper. The evidence is presented in Table 20. The most important result is that, if entered on its own as in regression (15), the Gini index fails to be significant and therefore has no explanatory power at all. The failure to confirm the proposed relationship means that the logic of self-interest is not sufficient to explain calls for redistribution. The equation only becomes significant when the three dummy variables are added, as in regression (16). The Gini index is significant, and so are the dummies, for transition and Anglo-Saxon countries. This in itself, from a rational choice perspective, is quite a remarkable finding. It indicates that, in a situation of similar inequality, people from different broadly defined cultural groupings have different preferences for redistribution. It may therefore be concluded that some factors contingent to these societies must have an influence that goes beyond the logic as described by Meltzer and Richard (1981).

Table 20. Support for domestic redistribution and level of inequality, aggregate level regression

\begin{tabular}{lcccccc}
\hline & \multicolumn{3}{c}{$(\mathbf{1 5 )}$} & \multicolumn{3}{c}{$(\mathbf{1 6})$} \\
\cline { 2 - 7 } & Coef. (b) & Std. err. & Sign. & Coef. (b) & Std. err. & Sign. \\
\hline Constant & 2.569 & 0.285 & 0.000 & 3.132 & 0.292 & 0.000 \\
Gini index & -1.105 & 0.825 & 0.193 & -3.074 & 1.019 & 0.007 \\
Dummy transition & & & & -0.309 & 0.122 & 0.019 \\
Dummy Anglo-Saxon & & & & 0.565 & 0.145 & 0.001 \\
Dummy developing & & & & 0.572 & 0.329 & 0.097 \\
R $^{2}$ (adjusted) & 0.031 & & 0.193 & 0.649 & & 0.000
\end{tabular}

Note: The dependent variable is "It is the responsibility of the government to reduce differences in income between people with high incomes and those with low incomes" (see Table 14). Based on aggregate level data set (excluding Cyprus, Italy, Netherlands, Portugal and Switzerland).

Source: Author's calculations based on ISSP data sets.

This leads back to the alternative explanation, namely normative considerations which, as demonstrated earlier, systematically vary between the four groups of countries. Regression (17) in Table 21 introduces the variable which, as argued above, captures value judgements

${ }^{9}$ See Aitchison and Brown (1957: 111 and 154). 
about inequality, that is the perception of income differences as being "too large", alongside the Gini coefficient. This equation is quite powerful and can account for 78.4 per cent of the overall variation between countries. The regression coefficient of just under one for the explanatory variable "Domestic inequality is too large" indicates that the assessment of inequality as being too high and support for redistribution follow each other quite closely. A step of one in the assessment of inequality leads to a step of roughly one in support for redistribution. Once again, the Gini index itself turns out to be insignificant. The equation changes little when the three dummy variables are introduced, as in regression (18). The dummies themselves show no significance, the Gini index remains insignificant and the coefficient for the assessment of domestic inequality as being "too large" decreases only slightly. It may therefore be concluded that, from a cross-country perspective, support for redistribution is largely a question of perceptions and judgements about inequality.

Table 21. Support for domestic redistribution and perception of inequality as "too large", aggregate level regression

\begin{tabular}{|c|c|c|c|c|c|c|}
\hline & \multicolumn{3}{|c|}{ (17) } & \multicolumn{3}{|c|}{ (18) } \\
\hline & Coef. (b) & Std. err. & Sign. & Coef. (b) & Std. err. & Sign. \\
\hline Constant & 0.527 & 0.259 & 0.054 & 0.949 & 0.583 & 0.119 \\
\hline $\begin{array}{l}\text { Domestic inequality } \\
\text { is "too large" }\end{array}$ & 0.998 & 0.108 & 0.000 & 0.795 & 0.196 & 0.001 \\
\hline Gini index & -0.378 & 0.397 & 0.352 & -0.676 & 0.974 & 0.496 \\
\hline Dummy transition & & & & -0.040 & 0.114 & 0.731 \\
\hline Dummy Anglo-Saxon & & & & 0.228 & 0.138 & 0.115 \\
\hline Dummy developing & & & & 0.031 & 0.283 & 0.913 \\
\hline $\mathrm{R}^{2}$ (adjusted) & 0.784 & & 0.000 & 0.797 & & 0.000 \\
\hline \multicolumn{7}{|c|}{$\begin{array}{l}\text { Note: The dependent variable is "It is the responsibility of the government to reduce differences in income between people with } \\
\text { high incomes and those with low incomes" (see Table 14). Based on aggregate level data set (excluding Cyprus, Italy, } \\
\text { Netherlands, Portugal and Switzerland). } \\
\text { Source: Author's calculations based on ISSP data sets. }\end{array}$} \\
\hline
\end{tabular}

However, this does not mean that self-interest plays no role in an individual's support for redistribution. Further conclusions can only be drawn from an analysis of individual level data sets. As outlined above, self-interest offers a potential rationale for the rich to oppose redistribution and the poor to call for it, and social class should be the variable that captures these effects. Two alternative operationalizations of these variables are included in the survey: family income and subjective self-placement. In the questionnaire, the wording for the latter is:

In our society there are groups which tend to be towards the top and groups which tend to be towards the bottom. Below is a scale that runs from top to bottom. Where would you put yourself on this scale?

Respondents are provided with ten boxes in a vertical arrangement with (1) labelled "top" and (10) labelled "bottom". Compared with family income, subjective self-placement has a number of advantages: 
- It is likely to mirror expectations of future earnings. An individual's present income is not only influenced by her or his social status, but also by her or his position in the life cycle. In most countries, a typical law or business student is likely to fall into the bottom income quintile, yet it would be misleading to think of her or him as belonging to the disadvantaged bottom stratum of society. After all, she or he is just building up a considerable stock of human capital. In the expectation of the future material benefits that she or he can reap, she or he is likely to place her or himself higher on the social scale than her or his present economic situation would allow. This is a welcome effect for the present research context, since self-interest should weaken support for redistribution in cases in which a higher future social position, and higher future earnings, can be reasonably expected.

- It records errors of judgement. Someone who mistakenly believes that she or he is better off than most others will place her or himself somewhere in the middle or upper part of the scale, even if her or his actual income falls far short of the average middleclass income. However, this error of judgement would lead her or him to believe that she or he would be among the net losers from redistribution and, according to the selfinterest theorem, she or he should oppose redistribution. Once again, this property of the questionnaire item is highly welcome.

In addition, there are some pragmatic reasons for preferring subjective self-placement to family income. In the first place, it avoids the problems of intra-household distribution and economies of scale in consumption. Respondents are far more eager to provide information on their self-placement than to disclose their family income (there are 2.9 per cent missing values for the former, compared with 12.6 per cent for the latter). Moreover, family income is not directly comparable across countries.

The questionnaire also asked respondents to record their social position ten years ago. This makes it possible to extend the analysis by introducing a variable which captures individual social mobility. Although this is not at the heart of the present research question, its inclusion avoids the omission of a variable that has been deemed crucial by several authors. Piketty (1995) suggests that people who have previously been members of a lower social class may have maintained their preference for redistribution, even though they are now better off and should oppose redistribution if they follow pure self-interest. In contrast, Alesina and Ferrara (2001) argue that experience of upward social mobility, and the expectation of further progress, should make it clear to an individual that efforts are rewarded and that redistribution is unnecessary. Rather than endeavouring to resolve this dispute here, social mobility is merely treated as an additional control variable.

Regressions (19) and (20) in Table 22 indeed confirm that respondents who place themselves in a higher social stratum support redistribution less than those who think of themselves as belonging to a lower social class. The sign of the coefficient is negative in both cases; the closer a respondent is to the top of the social scale (coded 1), the more likely she or he is to strongly disagree (coded 5) that governments should reduce differences in income. The effect becomes marginally weaker when the three country group dummies are added to the equation, due to the fact that people from Anglo-Saxon countries tend to place themselves higher on the social scale and are less supportive of redistribution, while the reverse holds true for people from transition countries (see Annex Table 3). The coefficient of -0.109 from regression (20) means that support for redistribution is roughly one point weaker at the very top than at the very bottom of the social scale, shifting for example from "strongly agree" towards "agree". However, both the top and bottom categories are barely populated (see Annex Table 3). The effect of social mobility is even weaker and switches sign when the group dummies are entered. Both variables taken together only explain 7.7 per cent of the overall variance, and the addition of the group dummies raises this to a mere 10.9 per cent. 
In comparison, the explanatory power of normative considerations is considerably higher. Controlling for the actual extent of inequality, the perception of domestic inequality as being "too large" can account for just under 30 per cent of the variance of the dependent variable. The coefficients of 0.650 and 0.603 in regressions (21) and (22) (both in Table 23) indicate that the negative assessment of current income differences translates almost one to one into the call on governments to take action to reduce inequality. Once again, there are some differences between the country groupings. All other things being equal, respondents from transition countries are more in favour of redistribution than those from the organized market economies (the omitted category), and people from Anglo-Saxon countries and the developing world view redistribution even less favourably.

Table 22. Support for domestic redistribution and social self-placement, individual level regression

\begin{tabular}{|c|c|c|c|c|c|c|}
\hline & \multicolumn{3}{|c|}{ (19) } & \multicolumn{3}{|c|}{ (20) } \\
\hline & Coef. (b) & Std. err. & Sign. & Coef. (b) & Std. err. & Sign. \\
\hline Constant & 3.027 & 0.023 & 0.000 & 2.878 & 0.025 & 0.000 \\
\hline Self-placement & -0.134 & 0.004 & 0.000 & -0.109 & 0.004 & 0.000 \\
\hline Progress (10 years) & -0.049 & 0.004 & 0.000 & 0.034 & 0.004 & 0.000 \\
\hline Dummy transition & & & & -0.227 & 0.016 & 0.000 \\
\hline Dummy Anglo-Saxon & & & & 0.354 & 0.017 & 0.000 \\
\hline Dummy developing & & & & -0.124 & 0.022 & 0.000 \\
\hline $\mathrm{R}^{2}$ (adjusted) & 0.077 & & 0.000 & 0.109 & & 0.000 \\
\hline \multicolumn{7}{|c|}{$\begin{array}{l}\text { Note: The dependent variable is "It is the responsibility of the government to reduce differences in income between people with } \\
\text { high incomes and those with low incomes" (see Table 14). Based on individual level data set. Number of valid observations } \geq \\
30,000 \text { (excluding Cyprus, Italy, Netherlands, Portugal and Switzerland). Weighted by weight2. } \\
\text { Source: Author's calculations based on ISSP data sets. }\end{array}$} \\
\hline
\end{tabular}

Table 23. Support for domestic redistribution and perception of inequality, individual level regression

\begin{tabular}{|c|c|c|c|c|c|c|}
\hline & \multicolumn{3}{|c|}{ (21) } & \multicolumn{3}{|c|}{ (22) } \\
\hline & Coef. (b) & Std. err. & Sign. & Coef. (b) & Std. err. & Sign. \\
\hline Constant & 1.230 & 0.024 & 0.000 & 1.468 & 0.038 & 0.000 \\
\hline $\begin{array}{l}\text { Domestic inequality } \\
\text { is "too large" }\end{array}$ & 0.650 & 0.006 & 0.000 & 0.603 & 0.006 & 0.000 \\
\hline Gini index & -0.613 & 0.058 & 0.000 & -1.256 & 0.120 & 0.000 \\
\hline Dummy transition & & & & -0.097 & 0.014 & 0.000 \\
\hline Dummy Anglo-Saxon & & & & 0.318 & 0.017 & 0.000 \\
\hline Dummy developing & & & & 0.171 & 0.038 & 0.000 \\
\hline $\mathrm{R}^{2}$ (adjusted) & 0.283 & & 0.000 & 0.299 & & 0.000 \\
\hline \multicolumn{7}{|c|}{$\begin{array}{l}\text { Note: The dependent variable is "It is the responsibility of government to reduce differences in income between people with high } \\
\text { incomes and those with low incomes" (see Table 14). Based on individual level data set. Number of valid observations } \geq 30,000 \\
\text { (excluding Cyprus, Italy, Netherlands, Portugal and Switzerlandl). Weighted by weight2. } \\
\text { Source: Author's calculations based on ISSP data sets. }\end{array}$} \\
\hline
\end{tabular}


When social position and progress are added alongside the assessment of inequality as being "too large", as is done in regressions (23) and (24) in Table 24, the explanatory power only rises marginally, suggesting that self-placement adds little. The coefficient for the variable "Domestic inequality is too large" also remains largely unchanged, although there is a very slight decrease (from 0.650 in regression 21 to 0.606 in regression 23), indicating that some of the effect that has previously been attributed to normative considerations is better captured by social self-placement. The regressions also allow a direct comparison to be made between the influence of normative considerations and social position. The absolute value of the former is about ten times higher than that of the latter. Moving a respondent from the very bottom of society to the very top would therefore have the same effect on her or his support for redistribution as changing her or his perception of inequality being too large from "strongly agree" towards "agree". Once again, this confirms the power of factor norms and values in explaining attitudes towards redistribution.

Table 24. Support for domestic redistribution, perception of inequality and social self-placement, individual level regression

\begin{tabular}{|c|c|c|c|c|c|c|}
\hline & \multicolumn{3}{|c|}{ (23) } & \multicolumn{3}{|c|}{ (24) } \\
\hline & Coef. (b) & Std. err. & Sign. & Coef. (b) & Std. err. & Sign. \\
\hline Constant & 1.630 & 0.031 & 0.000 & 1.706 & 0.044 & 0.000 \\
\hline $\begin{array}{l}\text { Domestic inequality } \\
\text { is "too large" }\end{array}$ & 0.606 & 0.006 & 0.000 & 0.581 & 0.006 & 0.000 \\
\hline Gini index & -0.370 & 0.060 & 0.000 & -0.870 & 0.125 & 0.000 \\
\hline Self-placement & -0.065 & 0.004 & 0.000 & -0.055 & 0.004 & 0.000 \\
\hline Progress (10 years) & -0.028 & 0.003 & 0.000 & 0.024 & 0.003 & 0.000 \\
\hline Dummy transition & & & & -0.021 & 0.015 & 0.164 \\
\hline Dummy Anglo-Saxon & & & & 0.287 & 0.017 & 0.000 \\
\hline Dummy developing & & & & 0.137 & 0.039 & 0.001 \\
\hline $\mathrm{R}^{2}$ (adjusted) & 0.300 & & 0.000 & 0.309 & & 0.000 \\
\hline \multicolumn{7}{|c|}{$\begin{array}{l}\text { Note: The dependent variable is "It is the responsibility of the government to reduce differences in income between people with } \\
\text { high incomes and those with low incomes" (see Table 14). Based on individual level data set. Number of valid observations } \geq \\
30,000 \text { (excluding Cyprus, Italy, Netherlands, Portugal and Switzerland). Weighted by weight2. } \\
\text { Source: Author's calculations based on ISSP data sets. }\end{array}$} \\
\hline
\end{tabular}

The main finding of this section is that explanations which rely solely on self-interest to explain support for redistribution are missing an important part of the picture. Indeed, theories that draw exclusively on this assumption produce results that are outright misleading. Normative considerations, as they emerge in the value judgement that inequality is too high, have quite a strong influence on the demand that governments should take action to reduce inequality. This is why even some of those who place themselves at the very top of society are in favour of redistribution, even though it is not in their narrowly defined selfinterest (see also Annex Table 4). 
When Harold Wilson wrote of the vast differences between rich and poor countries half a century ago, he concluded that "[c]ivilized countries, proud of their record in narrowing the gap between the richest and the poorest of their citizens, would never tolerate such contrasts of wealth and poverty within their borders" (Wilson, 1953: 12). Bridging the gap between poor and rich countries, or staging a "war on world poverty", as suggested by the title of his book, was the goal for which he argued passionately. "It is not a question of self-interest or power politics. It is a moral imperative. We are rich and they are poor, and it is our duty to help them." (ibid.: 25)

Since then the gap has widened. According to World Bank figures, the ratio of mean income in the richest 20 countries to that of the poorest 20 countries more than doubled between 1960 and 1995 alone, from 18 to 37 (World Bank, 2000: 51). The case for international redistribution therefore seems all the more urgent today. White (2001) shows how huge the poverty alleviating effect of even minor redistribution could be, and he calls for efficient channels for such redistribution to be discussed and evaluated more prominently. This section evaluates how supportive public opinion is of this call.

The ISSP module on social inequality included a question which explicitly dealt with international redistribution:

People in wealthy countries should make an additional tax contribution to help people in poor countries.

Respondents were again asked to use the familiar response categories, ranging from "strongly agree" (1) to "strongly disagree" (5). Unlike the question on domestic redistribution, which only stated the general objective, namely to reduce the differences in income between people with high incomes and those with low incomes, this question refers to a specific tool, an additional tax contribution, rather than choosing a neutral wording. This is very unfortunate, as many would argue that the lowering of customs barriers, changes in patent laws, technology transfers and even a relaxation of immigration controls are far more powerful and efficient tools than direct financial transfers. Faced with the single option of supporting additional taxes, people who agree with the objective, but disapprove of the tool, are therefore inclined to disagree with the statement. This question is therefore likely to under-record support for international redistribution. However, this can also be seen in a more positive light. Respondents in rich countries who are prepared to make a personal financial contribution voice very strong support for international redistribution, and support would be even greater if other less intrusive instruments were to be proposed. Support for higher taxes is generally very rare. 
Bearing in mind these methodological remarks, Table 25 offers some quite surprising figures. Support for additional taxes, at 47.0 per cent, is actually stronger than opposition to them, which stands at 30.3 per cent, with the rest being undecided. When the three developing countries are excluded, these figures change slightly to 45.7 per cent agreement and 32.6 per cent disagreement (not tabulated), but there remains a relative majority in favour of an international redistributive tax among those who would be likely to pay for it. It is no surprise that support, at around three quarters, is strongest in the developing world. But respondents in Spain and Slovenia are also in favour to the same level. At over 60 per cent, Cyprus, Northern Ireland and Portugal also have sound majorities in favour of the proposal. The strongest opposition is found in Latvia. Other countries in which respondents disagreeing with the proposal outnumber those supporting an international redistributive tax are Austria, Canada, Hungary, Israel, Japan, New Zealand and the United States. Except for the strong support from developing countries, there seems to be no obvious pattern in these responses. Nevertheless, the next section endeavours to identify factors which help explain the differences between countries. 
Table 25. Support for international redistribution, 1999

\begin{tabular}{|c|c|c|c|}
\hline & Agreement & Disagreement & Mean \\
\hline Australia & 41.1 & 32.2 & 2.86 \\
\hline Austria & 37.3 & 44.6 & 3.15 \\
\hline Brazil & 78.0 & 14.7 & 1.90 \\
\hline Bulgaria & 54.2 & 31.8 & 2.68 \\
\hline Canada & 31.5 & 45.4 & 3.18 \\
\hline Chile & 77.7 & 12.0 & 2.10 \\
\hline Cyprus & 62.7 & 18.2 & 2.40 \\
\hline Czech Republic & 43.4 & 33.5 & 2.83 \\
\hline France & 42.0 & 33.3 & 2.85 \\
\hline Germany East & 47.5 & 28.1 & 2.77 \\
\hline Germany West & 39.1 & 35.9 & 2.94 \\
\hline Great Britain & 47.5 & 29.4 & 2.75 \\
\hline Hungary & 33.8 & 45.9 & 3.20 \\
\hline Israel & 40.5 & 46.4 & 3.04 \\
\hline Japan & 26.1 & 35.6 & 3.22 \\
\hline Latvia & 26.9 & 57.3 & 3.42 \\
\hline New Zealand & 32.4 & 43.9 & 3.09 \\
\hline Northern Ireland & 60.2 & 18.8 & 2.43 \\
\hline Norway & 38.9 & 34.0 & 2.93 \\
\hline Philippines & 75.5 & 6.6 & 2.06 \\
\hline Poland & 54.1 & 18.4 & 2.51 \\
\hline Portugal & 61.5 & 28.0 & 2.44 \\
\hline Russian Federation & 45.0 & 38.4 & 2.90 \\
\hline Slovakia & 49.0 & 33.2 & 2.73 \\
\hline Slovenia & 73.9 & 10.6 & 2.12 \\
\hline Spain & 76.6 & 9.1 & 2.08 \\
\hline Sweden & 39.7 & 26.0 & 2.81 \\
\hline United States & 36.5 & 37.3 & 3.01 \\
\hline Average & 47.0 & 30.3 & 2.73 \\
\hline \multicolumn{4}{|c|}{$\begin{array}{l}\text { Note: Respondents were asked to comment on the following statement: "People in wealthy countries should make an additional } \\
\text { tax contribution to help people in poor countries". The answer categories given were "strongly agree" (1), "agree" (2), "neither } \\
\text { agree nor disagree" (3), "disagree" (4) and "strongly disagree" (5). For this Table, categories (1) and (2) were collapsed into } \\
\text { "agreement" and (4) and (5) into "disagreement". "Mean" is the simple average value for all answers from a given country. } \\
\text { Weighted by weight1. } \\
\text { Source: Author's calculations based on ISSP data sets. }\end{array}$} \\
\hline
\end{tabular}




\subsection{Explaining support for international redistribution: what are the views of people from rich countries?}

As has already been argued when seeking the reasons why people support domestic redistribution, two principal factors could also explain support for international redistribution:

- Normative considerations. Support for international redistribution could depend on the perception by citizens of international inequality. Only those who think that differences between rich and poor countries are "too large" should also be willing to support additional taxes in wealthy countries.

- Self-interest. Support for international redistribution could also vary with the expected benefits and costs to the respondent's home country. In this case, only people in poor countries should support international redistribution, since they are the ones who will benefit, while people in rich countries should oppose it.

A first impression of the relationship between the prosperity of a country and its support for an international redistributive tax can be gained from Figure 4, which plots mean support against per capita income in purchasing power parities based on the World Development Indicators 2002 (World Bank, 2002). On the right of the Figure, there is quite a dense cluster of countries in which respondents are, with a mean of around three on a five point scale, roughly equally divided into supporters and opponents of international redistribution. 
Figure 4: Per capita income and support for international redistribution

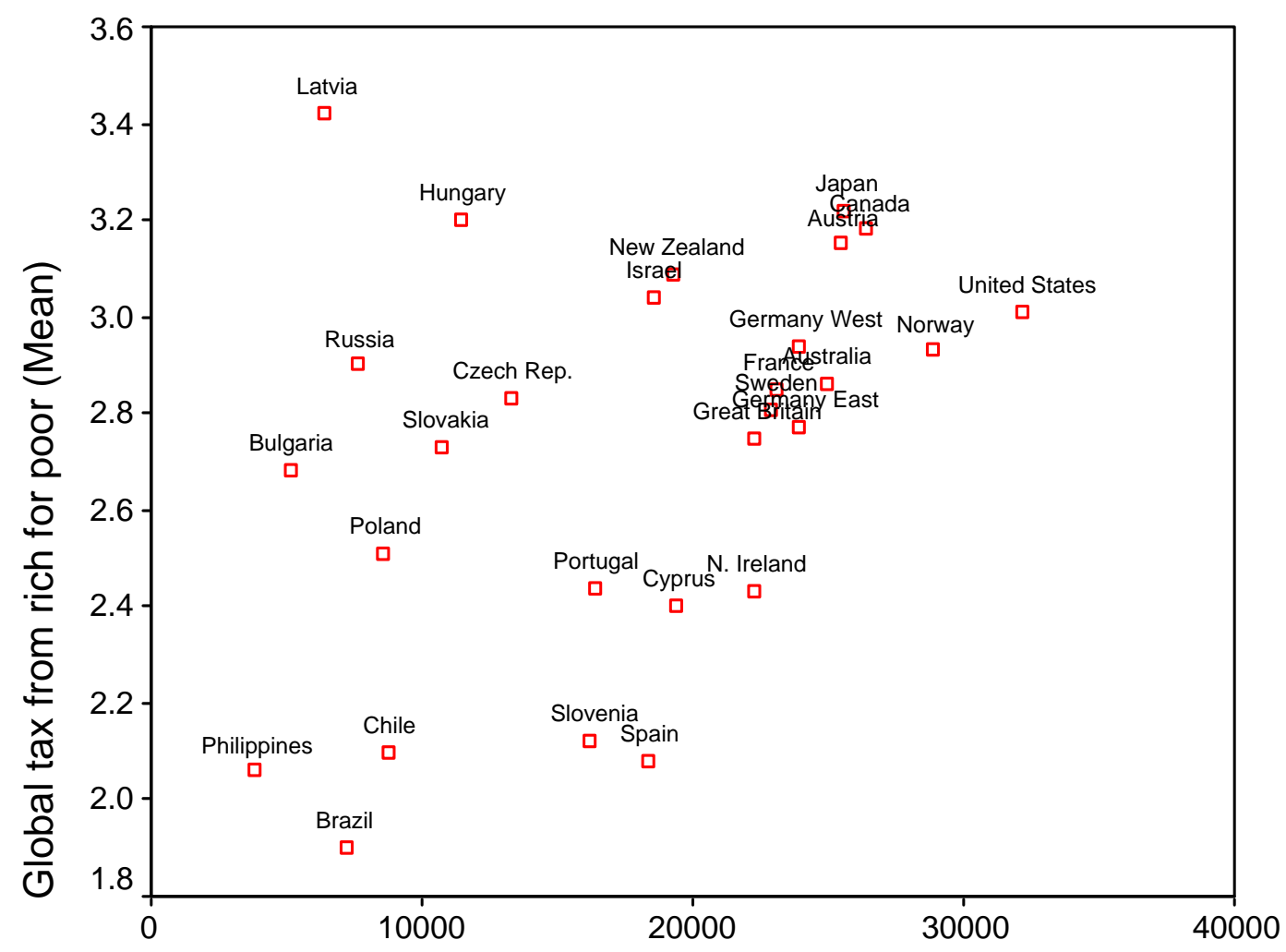

Per capita GDP in PPP\$ (1999)

As noted above, support is far higher in a number of almost equally wealthy countries (Cyprus, Portugal, Northern Ireland, Slovenia and Spain). Things become even more counter-intuitive towards the left of the Figure. At very similar income levels, people in Latvia (6428 PPP\$ per capita) are the strongest opponents of international redistribution, while those in Brazil (7173 PPP\$ per capita) almost unanimously support it. This already indicates that the level of income alone cannot account for the variance between countries.

At the aggregate level, there is nevertheless a relationship between income and support for international redistribution, as shown by regression (25) in Table 26. However, the significance of the coefficient on income per capita should be interpreted with caution due to heteroscedasticity problems that are apparent from Figure 4. Moreover, the variable "income per capita" loses its significance once the country group dummies are introduced, as in regression (26), and the only explanatory variable that turns out to be significant at the 0.10 -level is the dummy for the developing countries. Once the difference between developing and developed countries is taken into account, income cannot therefore explain the variations in support. The assessment of international inequality as being "too large", which was linked to the alternative explanation, also fails to explain why support differs between countries. It is insignificant in regressions (27) and (28) in Table 27, and again the only significant explanatory variable is the group dummy for developing countries. When per capita income and the assessment of international inequality are introduced together, as 
in the case of regressions (29) and (30) in Table 28, the picture changes little. Income is only significant as long as the group dummies are not included in the equation, and when they are introduced the sole significant variable is the group dummy for the developing countries. In all cases, the introduction of the group dummies raises the proportion of explained significance considerably. In short, aggregate level regressions can only confirm that people from developing countries are more in favour of international redistribution, but they do not explain why support differs greatly within the developed world.

Turning from countries to individual respondents, the picture changes slightly. Due to the greater number of cases, both of the principal explanatory variables gain in significance, whether entered on their own or together (see Tables 29 to 31). However, their explanatory power remains modest. The income level of the respondent's home country accounts for just 1.7 per cent of the variation in the dependent variable (regression 31) and the assessment that international inequality is too large is only slightly better at 5.5 per cent explained variance (regression 33). The coefficient for the variable "International inequality is too large" remains quite stable across all the different regressions at just under 0.40 , while for every step on the explanatory variable, support for international redistribution changes by almost 0.40 in the same direction. To achieve the same effect, it would be necessary to increase per capita income in a respondent's home country by 22,750 PPP\$ (regression 35), or an astonishing 70,000 PPP\$ when group dummies are entered, as they are in regression (36). Again, the dummy variable for developing countries produces comparatively large regression coefficients. Compared to a respondent from the market economies, the fact that a person is living in a developing country increases her or his support for international redistribution by between 0.603 (regression 32) and 0.793 points (regression 34) when other factors are controlled for.

Table 26. Per capita income and support for international redistribution, aggregate level regression

\begin{tabular}{lcccccc}
\hline & \multicolumn{3}{c}{ (25) } & \multicolumn{3}{c}{ (26) } \\
\cline { 2 - 7 } & Coef. (b) & Std. err. & Sign. & Coef. (b) & Std. err. & Sign. \\
\hline Constant & 2.380 & 0.177 & 0.000 & 2.563 & 0.348 & 0.000 \\
Income per capita & & & & & & \\
(in 10,000 PPP\$) & 0.198 & 0.092 & 0.040 & 0.100 & 0.149 & 0.508 \\
Dummy transition & & & & 0.117 & 0.224 & 0.606 \\
Dummy Anglo-Saxon & & & & 0.078 & 0.179 & 0.669 \\
Dummy developing & & & & -0.609 & 0.323 & 0.072 \\
$\mathrm{R}^{2}$ (adjusted) & 0.120 & & 0.040 & 0.297 & & 0.016 \\
Note: The dependent variable is "People in wealthy countries should make an additional tax contribution to help people in poor \\
countries". Based on aggregate level data set. \\
Source: Author's calculations based on ISSP data sets. & & & & & \\
\hline
\end{tabular}


Table 27. Assessment of international inequality as "too large" and support for international redistribution, aggregate level regression

\begin{tabular}{lcccccc}
\hline & \multicolumn{3}{c}{ (27) } & \multicolumn{3}{c}{ (28) } \\
\cline { 2 - 7 } & Coeef. (b) & Std. err. & Sign. & Coef. (b) & Std. err. & Sign. \\
\hline Constant & 2.573 & 0.533 & 0.000 & 2.697 & 0.561 & 0.000 \\
$\begin{array}{l}\text { International inequality } \\
\text { is "too large" }\end{array}$ & 0.092 & 0.312 & 0.771 & 0.054 & 0.338 & 0.873 \\
$\begin{array}{l}\text { Dummy transition } \\
\text { Dummy Anglo-Saxon }\end{array}$ & & & 0.014 & 0.160 & 0.933 \\
Dummy developing & & & 0.081 & 0.214 & 0.707 \\
$\mathrm{R}^{2}$ (adjusted) & & & & -0.771 & 0.228 & 0.003 \\
Note: The dependent variable is "People in wealthy countries should make an additional tax contribution to help people in poor \\
countries". Based on aggregate level data set. \\
Source: Author's calculations based on ISSP data sets.
\end{tabular}

Table 28. Assessment of international inequality as "too large", per capita income and support for international redistribution, aggregate level regression

\begin{tabular}{|c|c|c|c|c|c|c|}
\hline & \multicolumn{3}{|c|}{ (29) } & \multicolumn{3}{|c|}{ (30) } \\
\hline & Coef. (b) & Std. err. & Sign. & Coef. (b) & Std. err. & Sign. \\
\hline Constant & 2.644 & 0.499 & 0.000 & 2.563 & 0.607 & 0.000 \\
\hline $\begin{array}{l}\text { International inequality } \\
\text { is "too large" }\end{array}$ & -0.180 & 0.317 & 0.576 & 0.000 & 0.353 & 1.000 \\
\hline $\begin{array}{l}\text { Per capita income } \\
\text { (in 10,000 PPP\$) }\end{array}$ & 0.220 & 0.101 & 0.039 & 0.100 & 0.157 & 0.530 \\
\hline Dummy transition & & & & 0.117 & 0.229 & 0.614 \\
\hline Dummy Anglo-Saxon & & & & 0.077 & 0.217 & 0.724 \\
\hline Dummy developing & & & & -0.609 & 0.343 & 0.089 \\
\hline $\mathrm{R}^{2}$ (adjusted) & 0.096 & & 0.108 & 0.292 & & 0.025 \\
\hline
\end{tabular}


Table 29. Per capita income and support for international redistribution, individual level regression

\begin{tabular}{|c|c|c|c|c|c|c|}
\hline & \multicolumn{3}{|c|}{ (31) } & \multicolumn{3}{|c|}{ (32) } \\
\hline & Coef. (b) & Std. err. & Sign. & Coef. (b) & Std. Err.e & Sign. \\
\hline Constant & 2.359 & 0.017 & 0.000 & 2.559 & 0.037 & 0.000 \\
\hline $\begin{array}{l}\text { Per capita income } \\
\text { (in 10,000 PPP\$) }\end{array}$ & 0.206 & 0.009 & 0.000 & 0.100 & 0.016 & 0.000 \\
\hline Dummy transition & & & & 0.119 & 0.024 & 0.000 \\
\hline Dummy Anglo-Saxon & & & & 0.081 & 0.019 & 0.000 \\
\hline Dummy developing & & & & -0.603 & 0.034 & 0.000 \\
\hline $\mathrm{R}^{2}$ (adjusted) & 0.017 & & 0.000 & 0.041 & & 0.000 \\
\hline
\end{tabular}

Note: The dependent variable is "People in wealthy countries should make an additional tax contribution to help people in poor countries". Based on individual level data set, number of valid observations $\geq 30,000$. Weighted by weight2.

Source: Author's calculations based on ISSP data sets.

Table 30. Assessment of international inequality as "too large" and support for international redistribution, individual level regression

\begin{tabular}{lcccccc}
\hline & \multicolumn{3}{c}{$\mathbf{( 3 3 )}$} & \multicolumn{3}{c}{$\mathbf{( 3 4 )}$} \\
\cline { 2 - 7 } & Coef. (b) & Std. err & Sign. & Coef. (b) & Std. err. & Sign. \\
\hline Constant & 2.070 & 0.017 & 0.000 & 2.131 & 0.018 & 0.000 \\
International inequality is "too large" & 0.384 & 0.009 & 0.000 & 0.396 & 0.009 & 0.000 \\
Dummy transition & & & & 0.047 & 0.016 & 0.004 \\
Dummy Anglo-Saxon & & & & -0.034 & 0.018 & 0.065 \\
Dummy developing & & & & -0.793 & 0.023 & 0.000 \\
$R^{2}$ (adjusted) & 0.055 & & 0.000 & 0.096 & & 0.000
\end{tabular}

Note: The dependent variable is "People in wealthy countries should make an additional tax contribution to help people in poor countries". Based on individual level data set. Number of valid observations $\geq 30,000$. Weighted by weight2.

Source: Author's calculations based on ISSP data sets.

Table 31. Assessment of international inequality as "too large", per capita income and support for international redistribution, individual level regression
(35)
(36)

\begin{tabular}{lcccccc} 
& Coef. (b) & Std. err. & Sign. & Coef. (b) & Std. err. & Sign. \\
\hline Constant & 1.822 & 0.022 & 0.000 & 2.014 & 0.038 & 0.000 \\
International inequality is “too large” & 0.364 & 0.009 & 0.000 & 0.394 & 0.009 & 0.000 \\
Per capita income (in 10,000 PPP\$) & 0.160 & 0.009 & 0.000 & 0.054 & 0.016 & 0.001 \\
Dummy transition & & & & 0.104 & 0.023 & 0.000 \\
Dummy Anglo-Saxon & & & & -0.046 & 0.019 & 0.015 \\
Dummy developing & & & & -0.708 & 0.034 & 0.000 \\
$\mathbf{R}^{2}$ (adjusted) & 0.064 & & 0.000 & 0.096 & & 0.000
\end{tabular}

Note: The dependent variable is "People in wealthy countries should make an additional tax contribution to help people in poor countries". Based on individual level data set. Number of valid observations $\geq 30,000$. Weighted by weight2.

Source: Author's calculations based on ISSP data sets. 
However, a word of caution needs to be added when interpreting these figures. Compared to the regressions which sought to explain support for domestic redistribution, the overall explanatory power remains quite weak while the group dummies are excluded. This may in part be due to the very wording of the question, which is meant to capture support for international redistribution, but names a specific instrument (an additional tax) rather than stating the objective (reducing differences between rich and poor countries). The other explanation would be that the motivation for supporting or opposing international redistribution is only inadequately captured by variables in the questionnaire and per capita income. The opinion that income differences between countries are too large does not automatically lead respondents to support a global redistributive tax, but nor does living in a rich country make people rule out the transfer of income from rich to poor countries.

This does not, however, mean that no conclusions can be drawn concerning the reasons why people support an international redistributive tax and the role played in this respect by selfinterest and normative considerations. Self-interest can well explain why an overwhelming majority of people in the developing world welcome transfers to the poor countries. It can also explain why a strong minority in the rich countries oppose international redistribution. But it fails to explain why an even bigger group in the rich countries are prepared to support income redistribution. As these people will not benefit directly, they must have strong ethical or religious reasons that lead them to feel solidarity with those who are in a less fortunate position.

\section{Conclusion: How supportive is public opinion of a more inclusive and equitable path for globalization?}

This paper began by arguing that the issue of inequality within and between countries deserves special attention in the context of globalization. There is plenty of anecdotal evidence that this view is shared by many people around the world, ranging from the socalled "antiglobalization" activists in the North, labour union representatives in the South to African farmers demanding fairer trading conditions for their products. But unlike information on trade, foreign direct investment and similar aspects of globalization, which is readily available from standard statistical compilations, comparable cross-national data are more difficult to obtain on what people think about inequality in their own country, the widening gap between rich and poor countries and policy responses such as redistribution. Yet such information is of crucial importance when designing policies aimed at making globalization more inclusive and equitable. Do people share the view that inequality is a problem that needs remedying, or are they satisfied with current conditions? Can politicians count on public support for alternative policies? Can they afford to ignore the issue of inequality? Are people in the North blind to the huge income gap with the rest of the world, or do they have a sense of solidarity with those in the South who are less well-off?

There are, of course, no final answers to these questions, although this paper has attempted to shed some light on them. It has made available data from the three rounds of the module on social inequality of the International Social Survey Programme (ISSP). The surveys date back to 1987, 1992 and 1999 and cover some 30 countries from all continents, except for Africa. People's views, as they are recorded by the surveys, may provide guidance in two of the policy areas that emerged from the World Commission on the Social Dimension of Globalization, namely "globalization for all people" (policy area A) and "globalization and the political process" (policy area B). 
This area includes a focus on values which could underpin a more inclusive and equitable path for globalization, and the ISSP data contain information about the value judgements that people make about the present situation. There are very strong indications that the real situation does not meet with the values held by people around the world. For example, domestic inequality is perceived as being "too large" by a sound majority of just over 80 percent. The issue has become more urgent since the early stages of the current wave of globalization, and the current increases in inequality are a very likely factor behind this trend. However, there are certain differences between countries. Respondents from transition countries are the least prepared to accept inequality, while those from the AngloSaxon world and from the three developing countries in the sample show the greatest tolerance of inequality. The market economies of continental Europe, Japan and Israel are located between these extremes. Taking the difference between these groups of countries into account, a very regular pattern can be identified, namely that the higher the inequality, the more it is generally condemned.

People not only apply the beliefs that they hold about social justice consistently in their domestic environment, but they extend them to the global context. Those who care about inequality in their own country are also very likely to speak out against the global gap between rich and poor countries. Compared to this value component, the income level of a respondent's home country has only a minor influence on her or his perception of international inequality. In global terms, an overwhelming majority of nearly 90 per cent hold the view that economic differences between rich and poor countries are too large.

\section{Policy area B: Globalization and the political process}

This area explores, among other aspects, the role of parliaments and the manner in which global concerns relate to the national political agenda in different parts of the world. The argument put forward in the present paper is that the demands made by citizens on policymakers are an important part of the political process. In democracies, politicians have an incentive to be responsive to these demands in order to seek the support of voters and, when they want to push their own agenda, they need to evaluate how much support they can mobilize for their ideas. There is firm evidence that political action on inequality is one of the demands made by citizens and that policy makers have every reason to take this into account. On average, two-thirds of respondents think that it is the responsibility of their government to reduce income differences. The call for redistribution has become louder since 1987 and policy-makers today can less afford to ignore the social dimensions of the policies that they implement. Again, there are certain differences between countries. Eastern Europeans show the strongest support for redistribution, and support is weakest in the Anglo-Saxon countries. Self-interest is one motivation for the demand for redistribution, but it has been shown that normative considerations have a far bigger impact and can explain why redistribution finds some support even among those who occupy the top stratum of society. 
Although it is not surprising that support for international redistribution is highest in the developing world (at around 75 per cent), a similar majority in countries such as Spain and Slovenia support the proposal that people in rich countries should pay an additional tax contribution to help those in poor countries. In total, some 45.7 per cent of respondents from the developed and transition countries support this proposal, while 32.6 per cent oppose it. Considering that respondents were asked whether they wanted to pay more taxes, these figures provide quite impressive testimony of solidarity. If other less intrusive policy options with similar or greater effects could be found, it could reasonably be hoped that public support would exceed the level described above.

\subsection{The "post-report process"}

A large number factors will influence what has been referred to as the "post-report process", in terms of the process following the adoption of the final report of the World Commission on the Social Dimension of Globalization. One important aspect will certainly concern the level of public support for the World Commission's general objective of making globalization more inclusive and equitable. In this respect, the data presented in this paper are, on the whole, very encouraging. It would appear that, compared to the late 1980s, people are increasingly sharing a concern for inequality and are voicing a surprising degree of solidarity with those who have so far not gained from globalization. This offers a unique window of opportunity to win over citizens as allies in lobbying policy-makers for the implementation of the policies identified by the World Commission. If this potential is to be realized, it will be necessary to consider ways of disseminating the proposals of the World Commission beyond government bureaucracies and the narrow circles of specialized policy-makers so that they reach the broader groups of civil society.

While the important finding is that it can be hoped to mobilize support which would help to make a real impact on the future course of globalization, there is one qualification that needs to be made to this optimistic outlook: the citizens of the United States are different. ${ }^{10}$ They stand out even in comparison with those from other Anglo-Saxon countries. Despite the high level of inequality in the United States, agreement with the statement that income differences are too large is lower than anywhere else, and the United States is the only country in which a majority oppose domestic redistribution. A very similar picture emerges for the perception of international inequality: fewer people than anywhere else see economic differences between rich and poor countries as constituting a problem, and the level of support for international redistribution is consequently among the lowest of the countries surveyed. These differences have been discussed in the literature (see, for example, Roller, 2000; and Alesina and la Ferrara, 2001) and have also been mentioned throughout this paper. But, so far, the United States has been treated as just one of 30 countries. This may be justified from an academic perspective, but it ignores the fact that the United States has more political might and economic power than, for example, Latvia or Cyprus. When it comes to reshaping global arrangements to make them more favourable to poor countries (or more equitable within countries), proposals often come up against very strong opposition from the United States. The problem is that, as policy-makers in the United States face

10 This is, of course, entirely a question of perspective. In an NBER paper on inequality and happiness, Alesina, di Tella and MacCulloch (2001) conclude that "Europeans are different", which is how matters undoubtedly appear when viewed from Cambridge, Massachusetts. But in the present context the quote might have to be extended to read "Europeans are different, and so is pretty much everyone else". 
incentives at home that differ from those in Europe or Japan, they may be less prepared to accept proposals that are not in the immediate interests of their country. From their perspective, this behaviour is entirely rational, because they cannot rely on the backing of their voters to the same extent. However, it results in a situation in which policy-makers in the United States veto proposals that are seen as fair and acceptable elsewhere. One strategy may be to devise policy options that do not require unanimous support, but can have an impact when they are implemented by a sufficiently large number of countries in the North and the South. It is nevertheless important to emphasize once again that there is no automatic link between public opinion and policy decisions. Courageous leaders can choose to go ahead of public opinion and try to convince people of what they recognize as being the right thing to do. This may be more difficult in the United States than elsewhere, but there is no reason to believe that it is impossible. A strong minority in the United States is already in favour of redistributive policies. 


\section{References}

Aghion, Philippe, Caroli, Eve, and García-Peñalosa, Cecilia. 1999. "Inequality and economic growth: The perspective of the new growth theories", in Journal of Economic Literature. December, 37: 1615-1660.

Aitchison, J. and Brown, James A.C. 1957. The lognormal distribution. Cambridge, Cambridge University Press.

Alesina, Alberto, and Rodrik, Dani. 1994. "Distributive politics and economic growth", in Quarterly Journal of Economics. 109: 465-490.

Alesina, Alberto, and la Ferrara, Eliana. 2001. Preferences for redistribution in the land of opportunities. NBER Working Paper No. 8267. Cambridge, MA, National Bureau of Economic Research.

Alesina, Alberto, di Tella, Rafael, and MacCulloch, Robert. 2001. Inequality and happiness: Are Europeans and Americans different? NBER Working Paper No. 8198. Cambridge, MA, National Bureau of Economic Research.

Arts, Will, and Gelissen, John. 2001. "Welfare states, solidarity and justice principles: Does the type really matter?", in Acta Sociologica. 44(4): 283-299.

Boadway, Robin, and Keen, Michael. 2000. "Redistribution", in Atkinson, Anthony B., and Bourguignon, François (eds.), Handbook of income distribution. Vol. 1. Amsterdam, NorthHolland: 677-789.

Burniaux, Jean-Marc, Dang, Thai-Thanh, Fore, Douglas, Förster, Micheal, Mira d'Ercole, Marco, and Oxley, Howard. 1998. Income distribution and poverty in selected OECD countries. Economics Department Working Papers No. 189. Paris, OECD.

Chenery, Hollis, Ahluwalia, M., Bell, D., Duloy, J., and Jolly, R. 1974. Redistribution with growth. New York, Oxford University Press.

Clarke, George R. G. 1992. More evidence on income distribution and growth. Working Paper No. 1064. Washington, DC, World Bank.

Clauss, Günter, and Ebner, Heinz. 1972. Grundlagen der Statistik für Psychologen, Pädagogen und Soziologen. Frankfurt/Main and Zürich, Harri Deutsch.

Cornia, Giovanni Andrea. 2002. The impact of liberalisation and globalisation on income inequality in the developing and transitional economies. Paper prepared for the IPG-ILO. Florence and Geneva, University of Florence and ILO.

Downs, Anthony. 1957. An economic theory of democracy. New York, Harper and Row.

Esping-Andersen, Gøsta. 1990. The three worlds of welfare capitalism. Cambridge, Polity Press.

Gijsberts, Mérove. 1999. The legitimation of inequality in state-socialist and market societies, 19871996. PhD dissertation. Utrecht, University of Utrecht.

Hirschman, Albert O. 1973. "The changing tolerance for income inequality in the course of economic development", in Quarterly Journal of Economics. November, 87(4): 544-566.

Kaldor, Nicholas. 1958. "Capital accumulation and economic growth", reprinted in Kaldor, Nicholas (1978), Further essays on economic theory. New York, Holmes and Meier: 1-53.

Kluegel, James R., and Smith, Eliot R. 1986. Beliefs about inequality: Americans' views of what is and ought to be. New York, de Gruyter.

Kluegel, James R., and Mathìjù, Petr. 1995. "Egalitarian vs. inegalitarian principles of distributive justice", in Kluegel, James R., Mason, David, and Wegener, Bernd. (eds.), Social justice and political change: Public opinion in capitalist and post-communist States. Berlin and New York, de Gruyter: 209-238.

Kluegel, James R., Mason, David, and Wegener, Bernd. (eds.). 1995. Social justice and political change: Public opinion in capitalist and post-communist States. Berlin and New York, de Gruyter.

Meltzer, Allan H., and Richard, Scott F. 1981. "A rational theory of the size of government", in Journal of Political Economy. 89(5): 914-927. 
Milanovic, Branko. 2000. True world income distribution, 1988 and 1993: First calculations based on household surveys alone. Washington, DC, World Bank.

Piketty, Thomas. 1995. "Social mobility and redistributive politics", in Quarterly Journal of Economics. August, 110(3): 551-584.

Pitkin, Hanna F. 1967. The concept of representation. Berkeley, University of California Press.

Ravallion, Martin, and Lokshin, Michael. 1999. Who wants to redistribute? Russia's tunnel effect in 1990s. Policy Research Working Paper 2150. Washington, DC, World Bank.

Redmond, Gerry, Schnepf, Sylke V., and Suhrcke, Marc. 2002. Attitudes to inequality after ten years of transition. Innocenti Working Paper No. 88. Florence, UNICEF Innocenti Research Centre.

Roller, Edeltraud. 2000. "Marktwirtschaftliche und wohlfahrtsstaatliche Gerechtigkeitsprinzipien in Deutschland und den USA", in Gerhards, Jürgen (ed.), Die Vermessung kultureller Unterschiede. USA und Deutschland im Vergleich. Wiesbaden, Westdeutscher Verlag: 89-110.

Sen, Amartya. 2000. "Social justice and the distribution of income", in Atkinson, Anthony B., and Bourguignon, François (eds.), Handbook of income distribution. Vol. 1. Amsterdam, NorthHolland: 59-85.

Suhrcke, Marc. 2001. Preferences for inequality: East vs. West. Innocenti Working Paper No. 89. Florence, UNICEF Innocenti Research Centre.

Svallfors, Stefan. 1993. "Dimensions of inequality: A comparison of attitudes in Sweden and Britain", in European Sociological Review. 9(3): 267-287.

Toš, Niko, Mohler, Peter Ph., and Malnar, Brina (eds.). 1999. Modern society and values: A comparative analysis based on the ISSP project. Ljubljana and Mannheim: University of Ljubljana and ZUMA.

Wegener, Bernd, and Liebig, Stefan. 1995. "Dominant ideologies and the variation of distributive justice norms: A comparison of East and West Germany and the United States", in Kluegel, James R., Mason, David, and Wegener, Bernd (eds.), Social justice and political change: Public opinion in capitalist and post-communist States. Berlin and New York, de Gruyter: 239-259.

White, Howard. 2001. "National and international redistribution as tools for poverty reduction", in Journal of International Development. April, 13(3): 343-351.

Wilson, Harold. 1953. The war on world poverty: An appeal to the conscience of mankind. London, Victor Gollancz.

World Bank. 2000. World Development Report 2000/01: Attacking poverty. New York, Oxford University Press. 


\section{Data sources}

ISSP 1987, Social Inequality I, Central Archive for Empirical Social Research, University of Cologne, ZA No. 1680.

ISSP 1992, Social Inequality II, Central Archive for Empirical Social Research, University of Cologne, ZA No. 2310

ISSP 1999, Social Inequality III, Central Archive for Empirical Social Research, University of Cologne, ZA No. 3430.

Luxembourg Income Study (LIS), Income inequality measures, as of November 2002, available from http://www.lisproject.org/keyfigures/ineqtable.htm

OECD (1998): Income distribution and poverty in selected OECD countries. ECO/WKP (98) 2. Paris: OECD.

Statistics New Zealand (1999): New Zealand Now: Incomes. Wellington: Statistics New Zealand.

World Bank (2002): World Development Indicators 2002, CD-ROM. Washington, DC: World Bank.

World Income Inequality Database (WIID), Version 1.0 as of November 2002, available from http://www.undp.org/poverty/initiatives/wider/wiid.htm. 


\section{Annex tables}

Annex Table 1. Main characteristics of the ISSP data sets

\begin{tabular}{|c|c|c|c|c|c|c|}
\hline & 1987 & & 1992 & & 1999 & \\
\hline Australia & 1663 & & 2203 & & 1672 & \\
\hline Austria & 972 & $w$ & 1027 & w & 1016 & w \\
\hline \multicolumn{7}{|l|}{ Brazil } \\
\hline Bulgaria & & & & & 1102 & \\
\hline Canada & & & & w & 1974 & w \\
\hline Chile & & & & & 1503 & \\
\hline Cyprus & & & & & 1000 & \\
\hline Czechoslovakia & & & 1101 & & & \\
\hline Czech Republic & & & & & 1834 & \\
\hline France & & & & & 1889 & \\
\hline Germany East & & & 1094 & & 511 & \\
\hline Germany West & 1397 & & 2297 & & 921 & \\
\hline Great Britain & 1212 & $w$ & 1066 & w & 804 & w \\
\hline Hungary & 2606 & & 1250 & w & 1208 & w \\
\hline Israel & & & & & 1208 & \\
\hline Italy & 1027 & w & 996 & w & & \\
\hline Japan & & & & & 1325 & \\
\hline Latvia & & & & & 1100 & \\
\hline Netherlands & 1638 & & & & & \\
\hline New Zealand & & & 1239 & & 1108 & \\
\hline Northern Ireland & & & & & 830 & \\
\hline Norway & & & 1538 & w & 1268 & \\
\hline Philippines & & & 1200 & w & 1200 & w \\
\hline Poland & & & 1636 & w & 1135 & w \\
\hline Portugal & & & & & 1144 & w \\
\hline Russian Federation & & & 1983 & w & 1705 & w \\
\hline Slovakia & & & & & 1082 & \\
\hline Slovenia & & & 1049 & & 1006 & \\
\hline Spain & & & & & 1211 & w \\
\hline Sweden & & & 749 & w & 1150 & w \\
\hline Switzerland & 987 & & & & & \\
\hline United States & 1564 & w & 1273 & w & 1272 & \\
\hline Total & 13,066 & & 21,701 & & 33,178 & \\
\hline $\begin{array}{l}\text { Note: A "w" indicates th } \\
\text { Source: Author's calcul }\end{array}$ & & & & & & \\
\hline
\end{tabular}


Annex Table 2. Documentation of inequality data and sources (Gini coefficients for disposable household income per person)

\begin{tabular}{|c|c|c|c|c|c|c|c|c|c|c|c|c|c|c|c|c|c|c|c|}
\hline Country & Source & 1982 & 1983 & 1984 & 1985 & 1986 & 1987 & 1988 & 1989 & 1990 & 1991 & 1992 & 1993 & 1994 & 1995 & 1996 & 1997 & 1998 & 1999 \\
\hline Australia & LIS & & & & 0.292 & & 0.298 & & 0.304 & & & 0.308 & & 0.311 & & & & & $0.318^{*}$ \\
\hline Austria & LIS & & & & & & 0.227 & & & & & 0.258 & & & 0.277 & & & & 0.277 \\
\hline Brazil & WIID (gross) & & & & & & & & & & & & & & & 0.600 & & & 0.600 \\
\hline Bulgaria & WIID & & & & & & & & & & & 0.311 & 0.319 & 0.356 & 0.372 & 0.348 & 0.346 & & 0.346 \\
\hline Canada & LIS & & & & & & 0.283 & & & & 0.281 & 0.282 & & 0.285 & & & 0.291 & 0.305 & 0.305 \\
\hline Chile & WIID (gross) & & & & & & & & & & & & & & & 0.564 & & & 0.564 \\
\hline Czech Republic & LIS & & & & & & & & & & & 0.207 & & & & 0.259 & & & $0.269^{*}$ \\
\hline France & LIS & & & & & & & & 0.287 & & & & & 0.288 & & & & & 0.288 \\
\hline Germany & LIS & & & 0.249 & & & 0.248 & & 0.247 & & & & & 0.261 & & & & & 0.261 \\
\hline Hungary & LIS & & & & & & $0.273^{*}$ & & & & 0.283 & 0.296 & & 0.323 & & & & & $0.333^{*}$ \\
\hline Israel & LIS & & & & & 0.308 & & & & & & 0.305 & & & & & 0.336 & & 0.336 \\
\hline Italy & LIS & & & & & 0.306 & 0.303 & & & & 0.289 & 0.302 & & & 0.342 & & & & \\
\hline Japan & OECD (1998) & & & 0.252 & & & & & & & & & & 0.265 & & & & & 0.265 \\
\hline Latvia & WIID (unknown inc.) & & & & & & & & & & & & & & & & & 0.324 & 0.324 \\
\hline Netherlands & LIS & & 0.260 & & & & 0.256 & & & & 0.266 & & & 0.253 & & & & & \\
\hline New Zealand & Statistics New Zealand & 0.269 & & & & 0.264 & 0.274 & & & & 0.316 & 0.319 & & & & 0.331 & & & 0.331 \\
\hline Norway & LIS & & & & & 0.233 & 0.233 & & & & 0.231 & 0.233 & & & 0.238 & & & & 0.238 \\
\hline Philippines & WIID (gross) & & & & & & & & & & 0.468 & 0.462 & & 0.451 & & & 0.496 & & 0.496 \\
\hline Poland & LIS & & & & & 0.271 & 0.272 & & & & & 0.274 & & & 0.318 & & & & 0.294 \\
\hline Russian Fed. & LIS & & & & & & & & & & & 0.393 & & & 0.447 & & & & $0.457^{*}$ \\
\hline Slovakia & WIID & & & & & & & & & & & 0.186 & 0.197 & 0.208 & 0.200 & 0.248 & 0.234 & & 0.234 \\
\hline Slovenia & WIID & & & & & & & & & & 0.227 & 0.226 & 0.251 & 0.220 & 0.234 & 0.240 & & & 0.240 \\
\hline
\end{tabular}




\begin{tabular}{|c|c|c|c|c|c|c|c|c|c|c|c|c|c|c|c|c|c|c|c|c|}
\hline Country & & Source & 1982 & 1983 & 1984 & 1985 & 1986 & 1987 & 1988 & 1989 & 1990 & 1991 & 1992 & 1993 & 1994 & 1995 & 1996 & 1997 & 1998 & 1999 \\
\hline Spain & LIS & & & & & & & & & & 0.303 & & & & & & & & & 0.303 \\
\hline Sweden & LIS & & & & & & & 0.218 & & & & & 0.229 & & & 0.221 & & & & 0.221 \\
\hline Switzerland & LIS & & 0.309 & & & & & 0.308 & & & & & 0.307 & & & & & & & \\
\hline United Kingdom & LIS & & & & & & 0.303 & 0.310 & & & & 0.336 & 0.337 & & 0.339 & 0.344 & & & & 0.345 \\
\hline United States & LIS & & & & & & 0.335 & 0.335 & & & & 0.336 & 0.342 & & 0.355 & & & 0.372 & & 0.372 \\
\hline
\end{tabular}

Note: Figures in italics are based on interpolations between the closest preceding and closest following year or, in the case of 1999, refer to the closest year available. Extrapolations have only been made if evidence is available from an independent source that the past trend continued; these figures are marked with an asterisk ( ${ }^{*}$ ).

Sources: LIS refers to the Luxembourg Income Study as available from http://www.lisproject.org/keyfigures/inegtable.htm in November 2002 covering household disposable income per person (using the LIS equivalence scale); Statistics New Zealand refers to Statistics New Zealand (1999: 73) which produced LIS-equivalent Gini coefficients; OECD refers to Burniaux et al. (1998); and WIID refers to the World Income Inequality Database, Version 1.0 as of November 2002, available from http://www.undp.org/poverty/initiatives/wider/wiid.htm. 
Annex Table 3. Subjective self-placement, percentage distribution across country groups

\begin{tabular}{|c|c|c|c|c|c|}
\hline & & $\begin{array}{c}\text { Organized } \\
\text { market } \\
\text { economies }\end{array}$ & $\begin{array}{l}\text { Transition } \\
\text { countries }\end{array}$ & $\begin{array}{c}\text { Anglo- } \\
\text { Saxon } \\
\text { countries }\end{array}$ & $\begin{array}{l}\text { Developing } \\
\text { countries }\end{array}$ \\
\hline Top & \multirow[t]{9}{*}{ (1) } & 0.5 & 0.3 & 1.0 & 1.0 \\
\hline$(2)$ & & 1.1 & 0.4 & 2.0 & 1.2 \\
\hline (3) & & 6.7 & 2.3 & 8.6 & 2.9 \\
\hline (4) & & 14.2 & 6.1 & 16.9 & 5.2 \\
\hline (5) & & 33.9 & 21.2 & 32.8 & 19.2 \\
\hline (6) & & 16.4 & 15.9 & 15.8 & 15.5 \\
\hline (7) & & 12.4 & 17.6 & 11.3 & 15.2 \\
\hline (8) & & 8.5 & 16.4 & 6.5 & 17.2 \\
\hline (9) & & 3.4 & 10.9 & 3.5 & 10.3 \\
\hline Bottom & $(10)$ & 2.9 & 8.8 & 1.7 & 12.1 \\
\hline \multicolumn{2}{|c|}{ Mean self-placement } & 5.62 & 6.75 & 5.36 & 6.81 \\
\hline
\end{tabular}

Note: The questionnaire wording was as follows: "In our society there are groups which tend to be towards the top and groups which tend to be towards the bottom. Below is a scale that runs from top to bottom. Where would you put yourself on this scale?". Weighted by weight 2 .

Source: Author's calculations based on ISSP data sets.

\section{Annex Table 4. $\quad$ Support for redistribution by social stratum}

\begin{tabular}{|c|c|c|c|c|}
\hline & $\begin{array}{l}\text { Organized } \\
\text { market } \\
\text { economies }\end{array}$ & $\begin{array}{l}\text { Transition } \\
\text { countries }\end{array}$ & $\begin{array}{l}\text { Anglo- } \\
\text { Saxon } \\
\text { countries }\end{array}$ & $\begin{array}{l}\text { Developing } \\
\text { countries }\end{array}$ \\
\hline Top & 63.3 & 75.0 & 33.9 & 71.4 \\
\hline (2) & 53.7 & 59.1 & 31.9 & 88.1 \\
\hline (3) & 50.1 & 58.0 & 37.4 & 66.0 \\
\hline (4) & 54.6 & 68.0 & 44.2 & 76.8 \\
\hline (5) & 68.2 & 74.9 & 51.8 & 66.0 \\
\hline (6) & 69.2 & 77.4 & 58.9 & 74.3 \\
\hline (7) & 74.1 & 80.3 & 62.7 & 77.9 \\
\hline (8) & 81.0 & 84.8 & 68.2 & 79.2 \\
\hline (9) & 82.8 & 90.4 & 65.6 & 79.1 \\
\hline Bottom & 82.7 & 93.8 & 74.3 & 83.7 \\
\hline Mean support (\%) & 67.7 & 80.3 & 52.9 & 75.7 \\
\hline \multicolumn{5}{|c|}{$\begin{array}{l}\text { Note: The percentage from each stratum that "agrees" or "strongly agrees" that governments should reduce income } \\
\text { differences is tabulated. The questionnaire wording for subjective self-placement was as follows: "In our society there } \\
\text { are groups which tend to be towards the top and groups which tend to be towards the bottom. Below is a scale that } \\
\text { runs from top to bottom. Where would you put yourself on this scale?". Weighted by weight2. } \\
\text { Source: Author's calculations based on ISSP data sets. }\end{array}$} \\
\hline
\end{tabular}




\section{Policy Integration Department Working Papers prepared for the World Commission on the Social Dimension of Globalization}

No. 16 International finance: Meeting the needs of people in developing countries, José Guilherme Almeida dos Reis

No. 17 The gender dimensions of the globalization of production, Stephanie Barrientos, Naila Kabeer and Naomi Hossain

No. 18 Social exclusion in the context of globalization, Jan Breman

No. 19 Gender and globalization: A macroeconomic perspective, Çağatay Nilüfer and Ertük Korkurt

No. 20 Globalization, social exclusion, and work: with special reference to informal employment and gender, Marilyn Carr and Martha Chen

No. 21 Resources for social development, Anthony Clunies Ross

No. 22 Does the new international trade regime leave room for industrialization policies in the middle-income countries?, Alisa DiCaprio and Alice Amsden

No. 23 Social dimension of globalization in Latin America: Lessons from Bolivia and Chile, Alvaro García Hurtado

No. 24 Globalization: Social impact and policy actions: A partly annotated bibliography, Bernhard Gunter and Rolph van der Hoeven

No. 25 The social dimension of global production systems, Susan Hayter

No. 26 Reforming global economic and social governance:

a critical review of recent programmatic thinking, Jeremy Heimans

No. 27 Corporate social responsibility: An issues paper, Michael Hopkins

No. 28 Upgrading in global value chains, John Humphrey

No. 29 Implications of globalization and economic restructuring for skills development in Sub-Sahara Africa, Richard K. Johanson

No. 30 The outcome and impact of the main international commissions on development issues, Frédéric Lapeyre

No. 31 Globalization and structural adjustment as a development tool, Frédéric Lapeyre

No. 32 Globalization and perceptions of social inequality, Malte Lübker

No. 33 The changing structure of trade linked to global production systems:

What are the policy implications?, William Milberg

No. 34 Corporate social responsibility: An overview of principles and practice, Jill Murray

No. 35 Inclusive development strategy in an era of globalization, Ignacy Sachs

No. 36 Social consequences of the globalization of the media and communications sector: Some strategic considerations, Seán Ó. Siochrú

No. 37 Globalization, history and international migration - A view from Latin America, Andrés Solimano

No. 38 Towards a different kind of globalization, or how the anti-globalizers view the world, Gijsbert van Liemt 
